\title{
The role of the housing market in workers' resilience to job displacement after firm bankruptcy ${ }^{\text {tर }}$
}

\author{
Jordy Meekes ${ }^{\mathrm{a}, \mathrm{b}, \mathrm{c}, *}$, Wolter H.J. Hassink ${ }^{\mathrm{b}, \mathrm{c}}$ \\ ${ }^{a}$ The University of Melbourne, Melbourne Institute of Applied Economic and Social Research, Melbourne, Australia \\ ${ }^{b}$ Utrecht University, Utrecht University School of Economics, Utrecht, the Netherlands \\ ${ }^{c}$ IZA - Institute of Labor Economics, Bonn, Germany
}

\begin{abstract}
We examine the role of the housing market in workers' adjustment to job displacement. Dutch administrative monthly data were used and analysed with a quasi-experimental design involving job displacement. The estimates show that displaced workers, relative to comparable non-displaced workers, experience besides substantial losses in employment and wages also large increases in the commuting distance. Remarkably, we find that the displacement effect on the probability of changing home is negative. Thus for displaced workers commuting seems to be a more relevant margin of labour adjustment than changing home. The patterns in displacement effects change over the worker's post-displacement period - the negative effect on wages becomes more pronounced, whereas the increase in the commuting distance diminishes. The results suggest that displaced workers who are longer unemployed prefer working closer to home over higher wages. Also, we examine the role of workers' housing state in the displacement effects. We find that leveraged displaced owners, compared with displaced tenants and outright owners, are more rapidly re-employed and experience a smaller increase in the commuting distance but also a higher loss in wage.
\end{abstract}

Keywords:

Commuting distance, Geographic mobility, Housing state, Employment, Wages

JEL Classification:

J31, J32, J63, J65, R21, R23

\section{Introduction}

As in many other countries, the Dutch owner-occupied housing market and labour market suffered from strong negative developments during the Great Recession that started in 2008 (OECD, 2010). ${ }^{1}$ The large scale at which the transaction prices and home property values fell in the Dutch owner-occupied housing market is very rare - it previously occurred in the period 1978 to 1982 . The central question we address is how workers adjust after job displacement, by focusing on margins of adjustment that are related to space and the importance of workers' housing state. ${ }^{2}$ A better understanding of the use of margins

\footnotetext{
This article is based on a chapter in the dissertation of Meekes 2019. and forthcoming in the Journal of Urban Economics entitled "The role of the housing market in workers' resilience to job displacement after firm bankruptcy" (Meekes and Hassink 2018).

*Corresponding author. E-mail address: jordy.meekes@unimelb.edu.au

${ }^{1}$ In the Netherlands, the owner-occupied housing sector experienced a decline of almost 50 per cent in the number of transactions. Moreover, transaction prices decreased with over 20 per cent. The number of households with negative home equity, relative to the total number of owner-occupied households, increased from 13 per cent in 2008 to 34 per cent in 2014 . Unemployment rose from 3.4 per cent in the third quarter of 2008 to its peak of 8.1 per cent in the first quarter of 2014. The number of bankruptcies of firms increased from 3,589 in 2007 to 8,376 in 2013 (CBS 2018).

${ }^{2}$ We define the worker's housing state as being a tenant or owner-occupier, where owner-occupiers are classified in five different groups based on the loanto-value ratio on their home.
}

of adjustment by displaced workers is relevant for government policies that aim to limit the impact of negative employment shocks (Crépon and Van den Berg, 2016) and policies that affect housing state choice through subsidising homeownership or stimulating mortgage debt (DiPasquale and Glaeser, 1999).

Our first aim is to examine whether the spatial structure of homes and jobs represents relevant margins of adjustment for displaced workers. The literature on job displacement argues, based on human capital theory, that displaced workers lose human capital and wage premiums, and consequently experience substantial losses in post-displacement employment and wage outcomes (Hamermesh, 1987, Topel, 1990; Jacobson et al., 1993). The focus on losses in human capital, however, ignores the way displaced workers could use margins of adjustment related to space such as commuting patterns and household relocations to different homes, which are key to employment outcomes and wage dispersion. ${ }^{3}$ Indeed, Huttunen et al. (2018) show that job displacement increases household relocations to different homes, and argue that the losses in employment and income are highest for displaced workers who change home. Hence, Huttunen et al. (2018) suggest that displaced workers change home for

${ }^{3}$ See, e.g., $\operatorname{Zax}$ (1991); Simpson and Van der Veen 1992); Smith and Zenou (1997); Van Ommeren et al. (2000); Brueckner et al. (2002); Manning (2003); Smith and Zenou (2003); Fernandez and Su (2004); Van Ommeren and Fosgerau (2009); Mulalic et al. (2014). 
non-economic reasons such as family ties. We would argue that the commuting distance, compared to changing home, is a more relevant margin of labour adjustment for displaced workers, as displacement generates a negative income shock that lowers individuals' ability to change home. To better understand the use of margins of adjustment by displaced workers, we assess the displacement effects on employment, wages, commuting distance and changing home.

Our second aim is to examine the importance of workers' housing state for the displacement effects on employment, wages, commuting and changing home. The impact of workers' housing state on employment is theoretically ambiguous. On the one hand, homeowners relative to tenants, and mortgage owners relative to outright owners (i.e. owners who have paid off their entire mortgage), are less able to change home because of higher transaction costs and a more severe equity constraint (Stein 1995; Chan, 2001; Ferreira et al., 2010; Andersson and Mayock 2014). ${ }^{4}$ This geographic immobility could hinder employment prospects. On the other, homeowners, relative to tenants, may search more efficiently for jobs due to the use of more effective search methods (Goss and Phillips, 1997; Morescalchi, 2016). Moreover, mortgage owners, relative to outright owners, search more intensively for jobs due to differences in housing costs and payment obligations. In turn, the higher search efficiency or intensity could increase employment prospects. The difference in the exit rate into employment among displaced workers who differ in homeownership and home equity can thus be explained by differences in geographic mobility, search efficiency and search intensity. An alternative hypothesis is that unemployed workers who are highly leveraged and face a home equity constraint are more willing to accept a larger wage loss or a job that is further away. For example, Brown and Matsa (2017) show that unemployed workers who experience a home equity constraint are more willing to apply for positions that are closer in distance but pay lower wages. Ultimately, it is an empirical question how the worker's housing state affects the use of the margins of adjustment following job displacement.

For our empirical analysis, we created a monthly panel of employees based on rich administrative data sets that contain Dutch data of firms, employees and households in the period from January 2006 to December 2014. This time period is particularly suited as it includes the Great Recession and thereby allows us to incorporate data on the declining property values of homes and increasing number of bankruptcies of firms. We used data on job displacement due to firm bankruptcies (hereafter: job displacement) as an exogenous negative shock to the employment status of workers. The data on job displacement set the stage for a quasi-experimental design. This empirical design is important, since we examine incentive effects of workers' housing state in which endogenous selection into labour turnover should play no

\footnotetext{
${ }^{4}$ In contrast, several studies find that negative home equity positively affects geographic mobility by increasing the foreclosure and default rate (e.g., Coulson and Grieco 2013. Bricker and Bucks 2016. Demyanyk et al. 2017). In the Dutch institutional context, however, this mechanism is less relevant, as Dutch borrowers have full recourse loans and are characterised by a relatively low default and foreclosure rate (Steegmans and Hassink 2018).
}

role. However, there could exist confounding factors that affect the probability of job displacement. The potential of selection into job displacement based on observables was minimised by exact matching on coarsened observables of treated (displaced) to similar control (non-displaced) workers (Iacus et al., 2011). We included individual-specific fixed effects and applied the double-differences (DD) and triple-differences (DDD) estimator to control for various sources of unobserved heterogeneity.

The displaced and matched non-displaced workers are followed for eighteen months prior until thirty-six months after job displacement. The framework of the DD estimator was applied to the coarsened exact matched sample to estimate the displacement effects. The displacement effects are inferred from reduced-form models on four margins of adjustment, i.e. changes in employment, hourly wage, commuting distance and changing home. The DDD estimator was applied to assess the role of workers' housing state in the effects of job displacement. Workers' housing state was categorised by tenancy and homeownership, where owners were classified in five groups based on their loan-to-value ratio (hereafter: LTV) that was expressed as a percentage.

Our analysis provides two sets of novel results. First, the estimates show that commuting and household relocations to a different home are significant margins of adjustment in response to job displacement. Specifically, the average displacement effects we estimated show that displaced workers during the post-displacement period of thirty-six months, on average, (i) are about 25 percentage points less employed, (ii) experience a loss in wage of 6 per cent, (iii) experience an increase in the commuting distance of 3 kilometres and (iv) have a 0.06 percentage points lower probability of changing home. The displacement effects on employment and wage are consistent with those reported in the job displacement literature for European countries (e.g., see Schwerdt (2011); Huttunen et al. (2011); Ichino et al.(2017)). A novel finding of this paper is the increase in the commuting distance and decrease in changing home for workers who have been displaced, which represent compared to the mean value about a 20 per cent and 14 per cent change, respectively. This finding suggests that for displaced workers commuting is a more relevant margin of adjustment for economic reasons, whereas changing home might be more relevant for family reasons (Huttunen et al. 2018.$^{5}$ Also, the results reveal an interesting pattern over time since job displacement: the negative displacement effect on wages becomes more pronounced, whereas the positive effect on commuting distance becomes smaller. The first contribution of this paper is to document the spatial response to job displacement, which suggests that commuting is a more relevant

\footnotetext{
${ }^{5}$ The Dutch-specific institutional setting of the housing market is relevant for the interpretation of the effect of job displacement on changing home, and the role of the worker's housing state. Specifically, the Dutch housing market has: (i) No formal down-payment requirements. (ii) Owner-occupiers are characterised by relatively high LTV ratios. In 2011 there was a binding code of conduct for mortgages introduced, which set an LTV ratio limit at 106 per cent. (iii) Dutch households are characterised by low default and foreclosure rates, potentially due to the fact that all mortgage loans are full recourse loans (Ghent and Kudlyak 2011). (iv) Homeowners can deduct home mortgage interest from their taxable income. (v) the Dutch social rental sector is relatively large, as it represents over 35 per cent of all Dutch households (CBS 2018).
} 
margin of labour adjustment than changing home and that workers who are longer unemployed prefer working closer to home over higher wages.

Second, we find that workers' housing state plays a significant role in the displacement effects on employment, wages and the commuting distance, but not on the probability of changing home. We are not the first to examine the role of workers' housing state in employment outcomes. ${ }^{6}$ However, the literature ignores various selection problems that arise due to the correlations among workers' exit rate into unemployment, cause of unemployment and housing state choice. ${ }^{7}$ We contribute to this literature by exploiting a quasi-experimental design involving job displacement that eliminates the potential of endogenous selection into labour turnover. We find that displaced underwater owners (i.e. owners who face negative home equity), relative to displaced tenants, experience a 7 percentage points lower loss in employment. From the group of displaced homeowners, outright owners experience the highest loss in employment. Also, the results suggest that displaced tenants are more selective in post-displacement wages, and highly leveraged owners become employed relatively close to home. Displaced outright owners experience the highest increase in the commuting distance. The second contribution is to show that the effect of workers' housing state on the post-displacement outcomes in employment, wages and commute is substantial, and comparable in magnitude to that of other relevant characteristics such as gender and sector.

\section{Conceptual Framework}

In this section we discuss the conceptual considerations on the response to job displacement, which helps interpreting our empirical results. A search-theoretic model of the labour market focuses on the labour response to unemployment. The key choice behind the length of a worker's unemployment spell is whether employment is preferred to the alternative of remaining unemployed while searching for better job offers. We assume that the worker's reservation wage and spatial preferences are time-constant. A worker could increase the exit rate into employment through a high arrival rate of job offers by accepting a lower reservation wage or a higher search effort. This searchtheoretic model of the labour market, however, neglects the role of geography in the response to unemployment.

\subsection{A Spatial Response to Job Displacement}

From the demand side of the labour market, the set of potential job opportunities is increasing in the geographical scope of

\footnotetext{
${ }^{6}$ So far, there is abundant evidence of positive homeownership and mortgage effects on the exit rate into employment (e.g., Goss and Phillips 1997, Coulson and Fisher 2002 | Flatau et al. 2003,| Munch et al.| 2006 |Battu et al. 2008, | Baert et al. 2014 Caliendo et al. 2015 Morescalchi 2016). However, there is little to no evidence that negative home equity of homeowners affects the labour market. At the micro level, Valletta (2013) finds that being an underwater homeowner (i.e. an owner who faces negative home equity) does not affect the exit rate into employment. At the aggregate level, Kothari et al. (2013) and Modestino and Dennett (2013) find a very small impact of the lower mobility caused by the housing bust on the U.S. employment rate.

${ }^{7}$ For a discussion of these correlations, see, e.g., Van Leuvensteijn and Koning (2004); Munch et al. (2008); Moriizumi and Naoi (2011); Head and Lloyd-Ellis (2012); Bricker and Bucks (2016).
}

search. The geographical scope of search could be expanded by accepting a higher commuting distance while keeping the same home. Alternatively, the set of job opportunities and scope of search could be expanded by changing home. A larger set of job opportunities could lead to heterogeneity effects in the response to job displacement through wage differentials or quantity effects through employment differentials. Moreover, an initial increase in commute increases the likelihood of changing home, so that in the new home the commute distribution will be left shifted relative to those who do not change home. These mechanisms are consistent with the within-spatial equilibrium that implies that longer commutes are offset by higher wages or lower home prices (DiPasquale and Wheaton, 1996), and lead to the following predictions: (i) there is a positive correlation between wages and commute. In the context of job displacement, this positive correlation implies that the post-displacement loss in wages and increase in commuting distance are negatively correlated when holding the home constant. (ii) displaced workers who do not change home have a relatively large increase in commute.

From the supply side of the labour market, there is an ambiguous effect of increasing the set of job opportunities by expanding the region of job search. On the one hand, a larger set of job opportunities increases the exit rate into employment. On the other, a larger set of job opportunities leads to a higher reservation wage, which decreases the exit rate into employment. Similarly, a larger set of job opportunities might lead to a lower willingness to commute or lower willingness to change home. In this regard, there exist positive trade-offs between the reservation wage, the willingness to commute and the willingness to change home, as these are jointly determined by the worker (Van Ommeren and Rietveld, 2005, Mulalic et al., 2014; Mayock, 2015). Importantly, these trade-offs likely depend on the length of the post-displacement unemployment period. We assume that unemployment benefits become less generous over time since job displacement and are finite in time, consistent with the institutional setting of the Dutch labour market as discussed in Section 3.1, which would lead to a lower reservation wage over the unemployment spell. Conditional on the presence of transaction costs of changing home and assuming a fixed residential location, a worker will demand compensating differentials for lower wages in the form of a decrease in the commuting distance. This mechanism leads to an additional prediction: (iii) for workers who experience a longer unemployment duration the loss in wages becomes more pronounced, whereas the increase in commuting distance diminishes.

\subsection{Workers' Housing State and Job Displacement}

From the supply side of the labour market, the intensity and pay-offs of search could be endogenous to the worker's individual attributes, including their gender, education, age and housing state. We discuss the role of the worker's housing state in the response to job displacement.

The worker's housing state is relevant, because differences in payment obligations affect the financial incentive to become re-employed. We start our discussion from Munch et al. (2006), who compare unemployed homeowners to unemployed tenants 
and focus on the role of home changes in the exit rate into employment. They argue that homeowners experience a relatively high arrival rate of job offers, as they set relatively low reservation wages in order to avoid transaction costs of changing home to a distant labour market. Munch et al. (2006) show that homeowners, relative to tenants, have a higher exit rate into employment in their local labour market but a lower exit rate into employment in distant labour markets. Importantly, Munch et al. (2006) do not include commuting in their analysis, but do acknowledge that the commute margin is relevant. They argue that homeowners are more likely than tenants to use the commute margin if the costs of changing home are higher for homeowners.

We incorporate the commute response to job displacement and recognise that homeowners vary in the degree of leverage. Consider a displaced worker who is a mortgage owner. The unemployed mortgage owner faces a financial constraint and is obliged to amortise and pay off their mortgage. The payment obligations are likely to induce relatively high opportunity costs of continued unemployment and forgone wage. Conversely, displaced owners who have paid off their full mortgage have relatively weak financial incentives to become employed. A key question is how displaced workers who vary in the degree of leverage can increase their exit rate into employment. Morescalchi (2016) argues that unemployed leveraged owners search more intensively than other unemployed workers. If this holds, an unemployed mortgage owner is expected to have a relatively high arrival rate of job offers, keeping the reservation wage and the willingness to commute and change home constant. Alternatively, leveraged workers could increase the exit rate into employment by accepting a lower reservation wage, a higher commuting distance, or a relocation to a different home (Brown and Matsa, 2017). These mechanisms lead to the following prediction: (iv) more leveraged displaced workers have a higher exit rate into employment, but also experience a higher loss in wages or a higher increase in the commuting distance.

Finally: (v) the role of the unemployed worker's housing state in changing home is ambiguous. Unemployed leveraged owners, compared to unemployed outright owners, could be more willing to change home for employment reasons. However, they are less able to get a new mortgage or rental agreement for financial reasons, as they face a liquidity constraint. ${ }^{8}$ Note that in the Netherlands, negative home equity owners are unable to strategically default on their home, as all mortgages are full recourse loans.

\footnotetext{
${ }^{8}$ Alternatively, loss-averse workers could be less willing to change home as they face a prospective loss on their property (Genesove and Mayer 2001. Steegmans and Hassink 2018. Additional empirical analyses that are available upon request show that the importance of negative home equity and prospective losses for the post-displacement propensity to change home between NUTS 3 areas are comparable and negligible. The post-displacement propensity to change home within NUTS 3 areas is slightly lower for workers who face a prospective loss than for workers who face negative home equity.
}

\section{Institutional Background and Data}

\subsection{Institutional Setting of the Dutch Labour Market}

In the Netherlands, workers who are collectively displaced, for example through mass-layoffs, are protected by the Law Collective Redundancy Act (in Dutch: Wet Melding Collectief Ontslag). The Law Collective Redundancy Act does not hold for dismissals if the firm is declared bankrupt, as job displacement due to firm bankruptcy concerns an urgent case of displacement. This restriction has two implications for workers whose labour contract is terminated due to bankruptcy of the firm, and these implications are the reason we exploit the quasi-experimental design involving job displacement due to firm bankruptcy. ${ }^{9}$

First, the notification requirement to displaced workers, which is specified in the Law Collective Redundancy Act, applies only at the request of the Public Employment Service. Therefore, in general, no advance notification is required from bankrupt firms to displaced workers. Second, if a firm goes bankrupt, no severance or transition payments are provided by the firm to the displaced worker. These implications are important, as heterogeneity in the advance notification and severance pay can have a confounding effect on the post-displacement length of the unemployment spell and earnings (Addison and Portugal, 1987, Nord and Ting, 1991).

In the context of non-culpable job displacement such as displacement due to firm bankruptcy, the eligibility with respect to the length and amount of unemployment benefits is relevant. In the Netherlands, workers are eligible for one month of unemployment benefits for each year of job tenure, in which the worker was employed for at least 52 days, up to a maximum length of unemployment benefits of 38 months in total. The first two months of unemployment benefits are equal to 75 per cent of the average gross wage a worker has earned over the last twelve months. After two months of unemployment benefits, the unemployment benefits are paid out at 70 per cent.

\subsection{Institutional Setting of the Dutch Housing Market}

The institutional setting of the Dutch housing market has various characteristics that make it different from, e.g., the institutional setting of the U.S. housing market. First, in the Netherlands there is no formal down-payment requirement when buying a new home. Consequently, the probability of having a liquidity constraint to buy a new home is less likely. Second, Dutch homeowners are characterised by a relatively high LTV, as they can borrow more than the property value of the home. Only in August 2011 there was a binding code of conduct for mortgages introduced, which set an LTV limit at 106 per cent. Since 2012, the binding LTV limit of 106 per cent has been decreasing by 1 percentage point a year to 100 per cent in 2018. Third, all mortgage loans in the Netherlands are full recourse loans. Hence, the phenomenon of strategic defaults, i.e. walking away from a home with negative home equity, does

${ }^{9}$ For more information, see articles 3.1, 4.6 and $5 \mathrm{a} .2$ of the Law Collective Redundancy Act on http://wetten.overheid.nl/BWBR0003026/ 2018-01-01 
not exist. Fourth, homeowners in the Netherlands, but also in the U.S., can deduct home mortgage interest to reduce their taxable income. The deductibility of home mortgage interest stimulates mortgage debt. Finally, the social rental sector of the Dutch housing market is relatively large (CBS, 2018). In 2012, there were about 7,141,000 Dutch households. Of these households, approximately 59.32 per cent were owner-occupied and 40.68 per cent were being rented. Of the households that rent, 88.47 per cent rent social housing and 11.53 per cent rent private housing. ${ }^{10}$

\subsection{Data Sets}

We used various administrative data sets, retrieved from Statistics Netherlands, to create a monthly panel. The data sets we used contain data of individuals, households and firms over the time period 2006 to 2014 . We selected displaced workers whose job was terminated due to bankruptcy between July 2007 and December 2011. Each individual employee was followed for eighteen months prior until thirty-six months after the actual or potential job displacement. The actual month of job displacement of a displaced worker is equivalent to the potential month of displacement of a matched non-displaced worker. In Appendix A we provide additional information on the data construction and sample selections that were applied to create the appropriate sample of individual employees.

\subsection{Key Dependent Variables}

The key dependent variables, which represent the four margins of adjustment, were operated as follows. Employment status was expressed as a zero-one indicator variable that equals one if the individual is employed. The natural logarithm of the hourly wage was constructed by taking the natural logarithm of the monthly contractual gross wage relative to the monthly number of contractual hours worked. The commuting distance was calculated by taking the absolute distance between the central business district (CBD) of the work municipality and the CBD of the neighbourhood of the home. Note that the hourly wage and commuting distance of workers are observed conditional on employment. Unfortunately, the commuting distance is not observed for workers if they were not in the job in December, as the work location is administered only in December. The number of observations that are missing for the model in which commuting distance is the dependent variable, can be observed by the comparison with the model on hourly wage. ${ }^{11}$ See Table C.1 in Appendix $\mathrm{C}$ for the within change in the hourly wage and commuting distance for displaced and non-displaced workers. Home change was expressed as an indicator variable and equals one if the household has relocated.

\footnotetext{
${ }^{10}$ Note that tenants who rent social housing are less likely to change home than those who rent private housing, as social housing is less expensive and more difficult to acquire.

${ }^{11}$ See Table D.1 for the results using a sample where all individuals have complete information on commuting distance. We find similar results.
}

\subsection{Independent Variables and Covariates}

The set of key independent variables consists of variables that represent the treatment status, post-displacement status and housing state. The set of covariates consists of various demographic characteristics and job characteristics. All variables were expressed as zero-one indicator variables.

The treatment status is time-constant and equals one for workers who have been displaced. The post-displacement status equals one if the month under observation is after the month of job displacement. To assess the time dimension of the displacement effects, the post-displacement variable was in some of the models replaced by fifty-five indicator variables. The indicator variables reflect the time gap in months of the period since job displacement and range from minus eighteen to plus thirty-six, respectively. An indicator variable equals one if the period since job displacement corresponds to the given time gap.

Workers' housing state was used to approximate the workers' degree of household leverage and it was represented by six indicator variables. We distinguished between tenants and homeowners, where owners were categorised based on their LTV. Note that we were not able to distinguish between tenants who rent social or private housing. However, most tenants in our sample rent social housing, as 88.47 per cent of all Dutch tenants do so. The LTV, which is expressed as a percentage, was constructed by the observed mortgage loan relative to the property value of the home. The six indicator variables equal one if the worker is a tenant (base category), is an outright owner (i.e. an owner who has an LTV equal to 0 per cent on the home) and has an LTV between 0-33, 33-66, 66-100 and 100-133 per cent, respectively. ${ }^{12}$ Note that the so-called underwater homeowners have an LTV over 100 per cent on the home.

The set of demographic characteristics consists of indicators for gender, Dutch nationality, and age (21-30, 30-40, 40-50 and 50-60 years). The set of job characteristics represents the worker's time-invariant job characteristics in the month of job displacement, and consists of indicators for job tenure (3-6, 6-12, 12-18 and over 18 years) and industry (manufacturing and services sector). In addition, the set of covariates includes indicators for the year of job displacement, having children aged 18 or lower, having a partner, and the number of household members (1, 2, 3-4 and more than 4 members).

\section{Identification Strategy}

\subsection{Identification Challenges}

For our paper, the endogeneity problems of selection into labour turnover and selection into housing state required particular attention. Note that these selection issues are closely

\footnotetext{
${ }^{12}$ Unfortunately, the data on mortgage debt do not include the asset side in endowment mortgages. Hence, the levels of the mortgage debt were likely to be overestimated and the effect of workers' housing state is likely to be biased towards zero. To reduce the potential of the attenuation bias in the LTV, we operated housing state as a categorical variable. Table B.5 in Appendix B shows the results for an indicator variable that represents homeownership and a continuous variable that represents owners' LTV. The main conclusions of the paper are robust to the use of a continuous variable to represent owners' LTV.
} 
connected. For example, a sorting mechanism that is based on human capital or preferences for stability could simultaneously influence labour market outcomes and housing state choice (Flatau et al., 2003; Van Leuvensteijn and Koning, 2004, Munch et al., 2006, 2008; Moriizumi and Naoi, 2011; Head and Lloyd-Ellis, 2012; Bricker and Bucks, 2016). In this spirit, the likelihood of having a stable job, unemployment risk and housing state choice are likely to be correlated.

Selection issues are likely as various worker characteristics, for example age and gender (Kuhn, 2002, Von Wachter and Bender, 2006), job tenure (Farber 1999), and industry and education (Farber et al., 1993), affect the probability and cause of exit into unemployment. In turn, the selection issues could be problematic as the cause of unemployment affects, through signalling, the magnitude of displacement effects on post-unemployment labour market outcomes (Gibbons and Katz, 1991; Stevens, 1997; Kuhn 2002; Hu and Taber, 2011; Frederiksen et al., 2013). We controlled for the selection issues in various ways.

First, following the literature on job displacement, we deal with selection into labour turnover by using data on job displacement as an exogenous negative employment shock that set the stage for a quasi-experimental design (Eliason and Storrie, 2006). ${ }^{13}$ This empirical design limits the problem of confounding factors that affect post-displacement labour turnover, as displaced workers have an identical signalling value on labour market outcomes and typically do not get an advance notification or severance pay. In line with the job displacement literature, workers with a job spell of at least three years were selected for the group of displaced and non-displaced workers. ${ }^{14}$ Thereby, all workers had prior to job displacement a stable employment pattern and displacement was likely to be unforeseen. Furthermore, this sample selection reduces the potential of selection into housing state based on the belief of having a stable job.

Second, we deal with selection into job displacement based on observables, by applying Coarsened Exact Matching (CEM) that makes displaced and non-displaced workers balanced in covariates. CEM is a member of the class of Monotonic Imbalance Bounding matching methods and dominates the propensity score methods (Iacus et al., 2011). By balancing workers in covariates, the selection bias into displacement based on observables, which can arise from lack of common support, was greatly reduced (Heckman et al., 1997, 1998, Heckman and Smith, 1999). See Appendix F for additional information on how CEM was applied.

Third, to deal with bias based on unobserved heterogeneity, we apply the double-differences (DD) and triple-differences

\footnotetext{
${ }^{13}$ In our sample, workers were displaced between July, 2007 and December, 2011. Hence, there is variation over time in the variable that represents treatment of workers. This greatly reduces the potential of standard errors that understate the standard deviation of the estimator (Bertrand et al. 2004).

${ }^{14}$ In the Netherlands, workers are eligible for one month of unemployment benefits for each year of tenure in the job up to a maximum length of unemployment benefits of 38 months in total. The selection of job spells of at least three years ensures that all workers were eligible for unemployment benefits for the first three months after job displacement. By having a minimum benefits duration and controlling for the job tenure of the terminated job, we distance ourselves from the effect of benefits duration on post-unemployment labour market outcomes (Katz and Meyer 1990 Bover et al. 2002).
}

(DDD) estimator. DD was used to estimate the displacement effects, i.e. the change in outcome after treatment by comparing matched displaced to non-displaced workers. DDD was applied to examine the sources of differences in the displacement effects among workers who have been displaced. For example, the DDD estimate of a given housing state equals the difference between the DD estimate for the given housing state and the DD estimate for the reference category of housing state. The key identification restriction of the DD and DDD estimator requires that, conditional on observables, the change in outcomes of the displaced workers and non-displaced workers follow parallel paths. $^{15}$

Finally, we controlled for many factors that affect the exit rate into unemployment, likelihood of homeownership and the LTV on the home. For example, we controlled for changes in age and the presence of children aged 18 or lower. Moreover, indicator variables for calendar month (107) and NUTS 3 area (39) were included to capture business cycle effects and area-specific fixed effects, respectively. Individual-specific fixed effects were incorporated to eliminate bias from time-invariant unobserved heterogeneity, e.g., constant skill or worker preferences that might simultaneously affect housing state choice and labour market outcomes.

In two robustness checks, which are shown in Appendix B. we controlled for changes in the wealth position and duration of home occupancy, and for education level, respectively, to correct for unobserved heterogeneity driven by human capital. Note that we did include individual-specific fixed effects but did not control for education in the main part of our analysis, because data on education is only available for individuals if they received their diploma after the year 1995. The use of the education data would lead to a substantial selection issue, as less leveraged owners, especially outright owners, are relatively old and received their diploma before the year 1995 .

\subsection{Margins of Adjustment}

For each of the margins of adjustment a generic empirical model is specified to estimate the displacement effect. In what follows, $Y$ represents one of the four margins of adjustment employment, hourly wage, commuting distance and changing home. The empirical model is

$$
\begin{aligned}
Y_{i r t}= & \delta\left(\text { DISPLACED }_{i} \times \text { POST }_{i t}\right)+\rho \text { POST }_{i t} \\
& +\beta^{\prime} X_{i t}+\alpha_{i}+N_{r}+D_{t}+\varepsilon_{i r t}
\end{aligned}
$$

$i \in 1,2, \ldots, N ; r \in 1,2, \ldots, 40 ; t \in 1,2, \ldots, 108$

where subscripts $i, r$ and $t$ denote the worker, regional NUTS 3 area and month, respectively. The systematic differences in the outcome variables are captured by parameter $\delta$ of the two-way (double) interaction term between the scalar indicator variables DISPLACED and POST. The indicator variable DISPLACED is time-constant and equals one for workers who experienced job displacement. Note that the main effect of DISPLACED is

\footnotetext{
${ }^{15}$ See Section 5 for further discussion. See Figure D.1 for parallel predisplacement paths of displaced and non-displaced workers using a placebo treatment of the displaced twelve months prior to actual displacement.
} 
accounted for by including individual-specific fixed effects. The indicator variable POST equals one for the post-displacement period of thirty-six months after job displacement. The base and omitted categories of the variables DISPLACED and POST are the non-displaced and the pre-displacement period, respectively. The worker's housing state and covariates are represented by column vector $X$. The parameters of the covariates are represented by vector $\beta$. Individual-specific fixed effects are referred to by $\alpha . N_{r}$ represents indicators for the home location at the NUTS 3 level. Calendar month indicators are denoted by $D . \varepsilon$ refers to the idiosyncratic error term.

The second empirical model, shown in (2), is specified to assess whether the displacement effect is persistent over the period since job displacement. The empirical model is

$$
\begin{aligned}
Y_{i r t}= & \sum_{\tau=-18}^{36}\left[\delta^{\tau} \text { DISPLACED } D_{i} \times G_{i t}^{\tau}+\rho^{\tau} G_{i t}^{\tau}\right] \\
& +\beta^{\prime} X_{i t}+\alpha_{i}+N_{r}+D_{t}+\varepsilon_{i r t}
\end{aligned}
$$

where the time-dependent differences are captured using interaction terms among the indicator variables DISPLACED and $G^{\tau}$. The main parameters of interest are referred to by $\delta^{\tau}$. Parameter $\tau$ is defined as the time gap in months of the period since job displacement, which ranges from minus eighteen to plus thirtysix in increments of one. The negative values of $\tau$ correspond to the months prior to job displacement. Parameter $\tau$ equals zero in the actual and potential month of displacement for the displaced and non-displaced, respectively. The scalar indicator variable $G^{\tau}, \tau=-18, \ldots, 36$, refers to the $\tau$-th time gap between the month of job displacement and the month under observation. For example, indicator variable $G^{\tau=-12}$, which represents the base category, equals one if the period prior to job displacement is equal to twelve months. We used the twelfth month prior to job displacement as the base category, because workers might experience changes in outcomes close to the month of displacement in anticipation of the job displacement.

\subsection{Housing State and Margins of Adjustment}

We added various interaction terms to assess the sources of differences in the use of margins of adjustment by displaced workers. Workers are distinguished by their housing state, demographic characteristics and job characteristics. The empirical model in (3) complements the model in (1), by adding multiple three-way (triple) interaction terms among a vector of worker characteristics $X, D I S P L A C E D$ and POST. The vector $X$ includes time-varying variables (housing state and age) as well as time-invariant variables (gender, nationality and characteristics of the terminated job). The empirical model is

$$
\begin{aligned}
Y_{i r t}= & \left(\kappa^{\prime} X_{i t}\right) \times D_{I S P L A C E D_{i} \times P O S T} T_{i t} \\
& +\left(\gamma^{\prime} X_{i t}\right) \times D_{I S P L A C E D_{i}}+\left(\eta^{\prime} X_{i t}\right) \times \text { POST }_{i t} \\
& +\delta D I S P L A C E D_{i} \times P O S T_{i t}+\rho P O S T_{i t} \\
& +\beta^{\prime} X_{i t}+\alpha_{i}+N_{r}+D_{t}+\varepsilon_{i r t}
\end{aligned}
$$

where the parameters of interest are represented by vector $\kappa$.
The empirical model in (4) complements that of (2). The model in (4) is specified to assess the time dimension of the role of worker characteristics in the displacement effects. The time-dependent differences are captured by multiple three-way interaction terms among the indicator variables $X, D I S P L A C E D$ and $G^{\tau}$. The empirical model is

$$
\begin{aligned}
Y_{i r t}= & \sum_{\tau=-18}^{36}\left[\left(\kappa^{\prime \tau} X_{i t}\right) \times D I S P L A C E D_{i} \times G_{i t}^{\tau}\right. \\
& +\delta^{\tau} D I S P L A C E D_{i} \times G_{i t}^{\tau}+\left(\eta^{\prime \tau} X_{i t}\right) \times G_{i t}^{\tau} \\
& \left.+\rho^{\tau} G_{i t}^{\tau}\right]+\left(\gamma^{\prime} X_{i t}\right) \times D I S P L A C E D_{i} \\
& +\beta^{\prime} X_{i t}+\alpha_{i}+N_{r}+D_{t}+\varepsilon_{i r t}
\end{aligned}
$$

where the parameters of interest are denoted by vector $\kappa^{\tau}$.

\section{Empirical Results}

\subsection{Displacement Effects on the Margins of Adjustment}

We examine the displacement effects on the four margins of adjustment (see Eq. (1)). Columns (1), (2), (3) and (4) of Table 1 show the displacement effects on employment, hourly wage, commuting distance and changing home, respectively. For the variables displacement status (DISPLACED) and postdisplacement period (POST), the omitted categories are the nondisplaced workers and the pre-displacement period, respectively.

Table 1 shows that displaced workers are 25 percentage points less employed than non-displaced workers over the post-displacement period of thirty-six months. Moreover, reemployed displaced workers, compared with employed nondisplaced workers, experience a loss of about 6 per cent in hourly wage and an increase of 3 kilometres in the commuting distance. The increase of 3 kilometres in the commuting distance represents an increase of about 20 per cent, as the average commuting distance for displaced workers in the month of displacement equals 15 kilometres (see the summary statistics presented in Table C.3. Finally, we observe a negative displacement effect on the probability of changing home of 0.06 percentage points. The displacement effect on changing home corresponds to a decrease of about 14 per cent, as the mean changing probability for displaced workers in the month of displacement equals $0.0043 .{ }^{16}$

The negative displacement effect on changing home suggests that displaced workers, compared to non-displaced workers, are less able or willing to change home. This could be explained by the fact that displacement generates a negative income shock, which increases difficulties in financing a new home or signing a new rental agreement. In contrast to our findings, Huttunen et al. (2018) show, using Norwegian administrative data, that job displacement increases the propensity to change home between

\footnotetext{
${ }^{16}$ The results in Table 1 are robust to standard errors clustered by firm instead of by individual. The conclusion with respect to the displacement effect on commute is robust to the use of the natural logarithm of the commuting distance. These results are available upon request.
} 
Table 1

Displacement effects on the four margins of adjustment (Eq. (1)).

\begin{tabular}{|c|c|c|c|c|}
\hline & $\begin{array}{c}\text { Employment } \\
(=1)\end{array}$ & $\begin{array}{l}\text { Hourly wage } \\
(\log )\end{array}$ & $\begin{array}{c}\text { Commuting distance } \\
(\mathrm{km})\end{array}$ & $\begin{array}{l}\text { Home change } \\
(=1)\end{array}$ \\
\hline & $(1)$ & $(2)$ & (3) & $(4)$ \\
\hline DISPLACED $\times$ POST & $\begin{array}{c}-0.2531^{* * *} \\
(0.0026)\end{array}$ & $\begin{array}{c}-0.0625^{* * *} \\
(0.0017)\end{array}$ & $\begin{array}{l}3.1854^{* * *} \\
(0.2328)\end{array}$ & $\begin{array}{c}-0.0006^{* * *} \\
(0.0002)\end{array}$ \\
\hline Number of parameters & 161 & 161 & 161 & 161 \\
\hline Number of individuals & 54,229 & 54,229 & 54,229 & 54,229 \\
\hline Number of observations & $2,982,595$ & $2,719,570$ & $2,686,298$ & $2,982,595$ \\
\hline
\end{tabular}

Notes: Each column gives the dependent variable. Parameter estimates of the two-interaction term are reported. Clustered (by individual) standard errors are in parentheses. ${ }^{* * *},{ }^{* *},{ }^{*}$, correspond to the significance level of $1 \%, 5 \%, 10 \%$, respectively. The reference categories of DISPLACED and POST consist of the non-displaced workers and pre-displacement period, respectively. The regression analyses include individual-specific fixed effects and indicator variables for $P O S T$, housing state (5), age (3), children aged 18 or lower, partner, the number of household members (3), the NUTS 3 location of the household (39) and calendar month (107). The period under observation is from January 2006 to December 2014, in which displaced and non-displaced workers are observed for 18 months prior until 36 months after the actual and potential month of job displacement, respectively. Parameter estimates of the covariates are not reported.

local labour markets by about 30 per cent. ${ }^{17}$ They find that displaced workers who change home experience higher losses in employment and wages than stayers, and argue that workers are likely to change home for non-economic reasons such as family ties. An explanation for the difference in findings could be the fact that the surface area of the Netherlands is ten times as small as the surface area of Norway. This could make Dutch displaced workers relatively unwilling to change home for non-economic reasons such as family ties, as relatives are relatively close. An alternative explanation is the difference in the length of the postdisplacement period. The post-displacement period of thirty-six months we used could be too short to observe a displacement effect on household mobility. However, Huttunen et al. (2018) show that the increase in mobility takes place in the first two years after displacement. All in all, we argue that the commuting distance, compared to changing home, is a more relevant margin of labour adjustment for workers who have been displaced.

Figure 1 shows the context of changes in the outcome variables of matched displaced and non-displaced workers over the pre- and post-displacement period (see Eq. (2)). The fixed effects coefficients on employment and changing home are provided on the $y$-axis in percentage points (pp) in Figure 1A and Figure $1 \mathrm{D}$, respectively. The fixed effects coefficients on wages and the commuting distance are provided on the $\mathrm{y}$-axis in percentages $(\%)$ and kilometres $(\mathrm{km})$ in Figure 1B and Figure 1C, respectively. The $\mathrm{x}$-axis registers the time gap between the month of observation and the month of job displacement. The time gap equals zero in the month of actual and potential job displacement, for the displaced and non-displaced, respectively. Observe in Figure 1 parallel pre-displacement trends for the displaced and non-displaced workers in the outcome variables, which satisfy the identification restriction of the DD estimator. ${ }^{18}$

\footnotetext{
${ }^{17}$ Note that we estimate the displacement effect on changing home together for relocations within and between local labour markets. For an empirical model in which the dependent variable is operated as changing home between NUTS 3 areas, we find no significant displacement effect. This result is available upon request.

${ }^{18}$ Figure 1B shows a small hump in the monthly wage upon job displacement. Dutch salaries are supplemented with an $8 \%$ holiday allowance and also an end-of-year bonus that workers typically get paid out in May and December, respectively. The hump in wage can be explained by these bonuses, as they
}

In Figure 1A, the vertical line between months zero and one reveals the exit rate out of employment by the displaced workers. Twelve to twenty-four months after job displacement, the loss in employment is about 27 and 20 percentage points, respectively. This finding is consistent with those reported in the job displacement literature. For example, Schwerdt (2011) finds an effect of 23 percentage points over a post-displacement period of five years. Ichino et al.(2017) find a loss of 27 percentage points over the post-displacement period of twelve to twenty-four months.

Figure 1B shows a decrease in the wage loss between one and four months after job displacement. This decrease in wage loss could be explained by the low number of re-employed displaced workers, i.e. only 20 per cent of the displaced workers, one month after job displacement (see Figure 1A). Note that our paper is one of the few papers in the literature on job displacement that uses monthly data. For papers that use quarterly or annual data, such a pattern cannot be observed as the monthly variation is smoothed out. Importantly, after the fourth month since job displacement, the loss in wage increases over the postdisplacement period and ranges between 4 and 7 per cent (see Figure 1B). The estimates are in line with studies that examine the displacement effect on wage for Europe. For example, Schwerdt (2011) finds a wage loss due to job displacement, conditional on re-employment, of about 6 per cent. Huttunen et al. (2011) find a loss of 3 per cent in wage after 7 years. Note that studies that use U.S. data find higher wage losses due to the more centralised wage system (e.g., Couch and Placzek, 2010).

Figure $1 \mathrm{C}$ shows that displaced workers experience an increase in the commuting distance. However, after three months since job displacement, the increase in commute becomes smaller over the post-displacement spell. Note that Figure 1B and Figure $1 \mathrm{C}$ show composition effects that are caused by workers who exit unemployment, workers who experience job-to-job transitions and workers who change home.

We observe a small negative displacement effect, after six months since job displacement, on the probability of changing home (see Figure 1D). The finding suggests a delay in the im-

are paid upon displacement. Note that this hump underscores the importance of using the twelfth month prior to displacement as the reference month. See Deelen et al. (2014) for a similar finding using Dutch administrative data. 

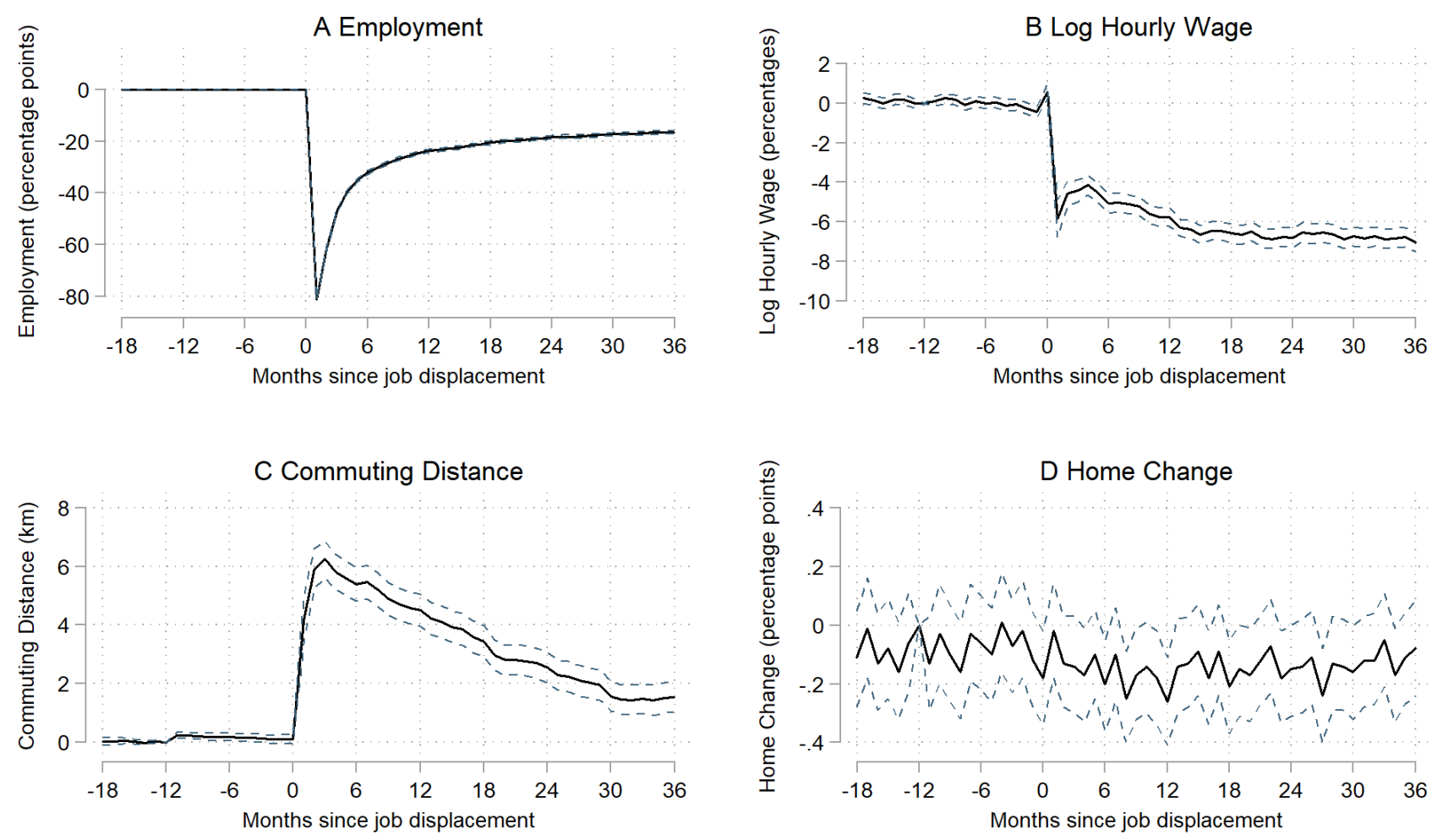

FE Coef.

95\% Conf. Int.

Fig. 1. Time-dependent displacement effects on employment (A), log hourly wage (B), commuting distance (C) and changing home (D) (Eq. (2)). Notes: Reference group is the group of non-displaced workers. Reference month is the twelfth month prior to job displacement. The $95 \%$ confidence intervals are computed using clustered standard errors by individual. All four fixed effects regression models include 266 parameters of which there are 54 two-way interaction terms. See Table 1 for additional notes and statistics.

pact of job displacement on the willingness or ability to change home. This delay can be explained by the fact that household relocations to a different home are characterised by a time gap between the month of transaction and the month of the actual home change, as the actual home change is realised once the home buyer registers his or her relocation at the local municipality. Note, however, that the 36 two-way interaction terms that capture the post-displacement effect on changing home are jointly insignificant.

Figure 2 provides estimates based on a sample in which we select displaced workers who are in their first job and/or did not change home after the incidence of job displacement. The observations of displaced workers who experience job-to-job transitions or home changes are excluded, which allows us to infer whether the composition effects are mainly driven by workers who exit unemployment and take up their first job since displacement. Indeed, Figure 1 and 2 reveal similar patterns, which suggest that the composition effects are almost entirely driven by workers who exit unemployment and not by job-to-job turnover or relocation to a different home.

All in all, the estimates provided in Figure 1B and Figure 1C reveal a novel pattern: displaced workers who have longer un- employment duration experience smaller increases in commute but higher losses in wage. To the best of our knowledge, this pattern has not been demonstrated in the literature.

\subsection{Housing State and the Use of Margins of Adjustment}

We examine the role of workers' housing state in the displacement effects on the margins of adjustment. To show the relative importance of workers' housing state, we also document the role of other sources of differences among workers in the displacement effects. The estimation results are displayed in Table 2 (see Eq. (3)). Workers' housing state is represented by LTV indicators and the reference category consists of workers who are tenants. ${ }^{19}$ The set of demographic characteristics includes FEMALE, AGE and DUTCH NATIONALITY, and the reference categories consist of workers who are male, aged 21 to 30 years and non-Dutch, respectively. The set of job characteristics includes TENURE and MANUFACTURING, and the reference

\footnotetext{
${ }^{19}$ We pool homeowners and tenants in our empirical models. The conclusions of our paper and the parallel trends in pre-displacement outcomes to satisfy the identification restrictions of the estimator are robust to stratifying the sample by each housing state and by comparing homeowners with tenants separately.
} 

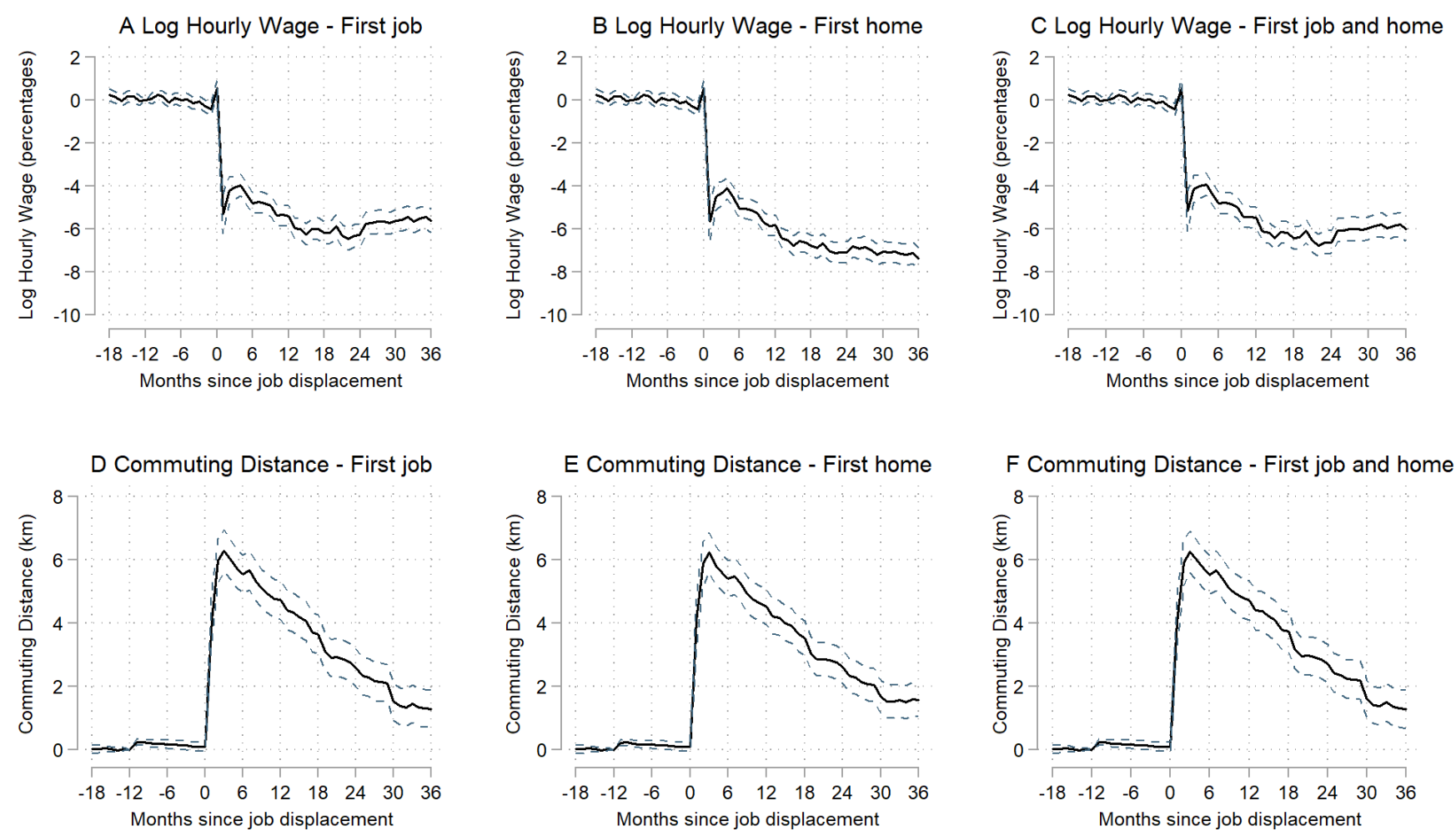

FE Coef.

95\% Conf. Int.

Fig. 2. Time-dependent displacement effects on log hourly wage (A, B and C) and commuting distance (D, E and F) (Eq. (2)). Notes: For A and D, the post-displacement observations are included conditional on being in the first post-displacement job. For B and E, the post-displacement observations are included conditional on not changed home. For $\mathrm{C}$ and $\mathrm{F}$, the post-displacement observations are included conditional on being in the first post-displacement job and not changed home. The number of individual-month observations for A-F equals 2,565,862, 2,691,495, 2,548,891, 2,544,658, 2,659,484 and 2,528,099, respectively. See Figure 1 for additional notes and statistics.

categories consist of workers who are 3 to 6 years in the job and active in the service sector, respectively. ${ }^{20}$

The estimates presented in Column (1) show the sources of differences in the displacement effect on employment. Compared with displaced workers who are tenants, underwater owners are about 7 percentage points more employed after displacement. Tenants incur a loss in employment comparable to outright owners. Interestingly, our findings are consistent with papers that find positive homeownership and mortgage effects on the unemployment duration, but at odds with the paper by Valletta (2013) who finds no significant effect of negative home equity on unemployment duration. The difference in results could be explained by our quasi-experimental design that reduces the potential of selection into labour turnover. Finally, the estimates in Column (1) show that displaced workers who are female, older,

\footnotetext{
${ }^{20}$ We positively evaluate the external validity of our analyses, as we find a comparable role of demographic and job characteristics in the losses in employment and wage to that in the literature (Madden |1987. Carrington |1993. Carrington and Zaman 1994 Chan and Stevens. 1999||2001||Eliason and Storrie 2006 Hijzen et al. 2010 . Tatsiramos. 2010. Hardoy and Schøne 2014. Hellerstein et al. |2016, Farber 2017).
}

non-Dutch and high-tenured experience a relatively high loss in employment. The importance of workers' housing state for the displacement effect on employment is substantial and comparable to that of other worker characteristics such as gender and tenure in the job.

The parameter estimates in Column (2) highlight the role of worker characteristics in the displacement effect on hourly wage. Compared with displaced tenants and owners who have an LTV between 0 per cent and 33 per cent, displaced outright owners and owners with an LTV over 33 per cent experience a 1 to 2 percentage points higher loss in hourly wage. The estimates suggest that more leveraged owners are less selective in wages when choosing jobs after job displacement. ${ }^{21}$ Moreover, the estimates in Column (2) show that the loss in hourly wage increases with age and tenure in the job, and is higher for displaced workers who are active in the manufacturing sector compared with workers who are active in the service sector. To the best of our

\footnotetext{
${ }^{21}$ The results indicate that the loss in employment is decreasing and the loss in wages is increasing in the worker's LTV. This observation is supported by the results in Table B.1 of Appendix B, where we control for workers' non-housing wealth and duration of home occupancy.
} 
Table 2

The role of observed worker characteristics in the effects of job displacement (Eq. (3)).

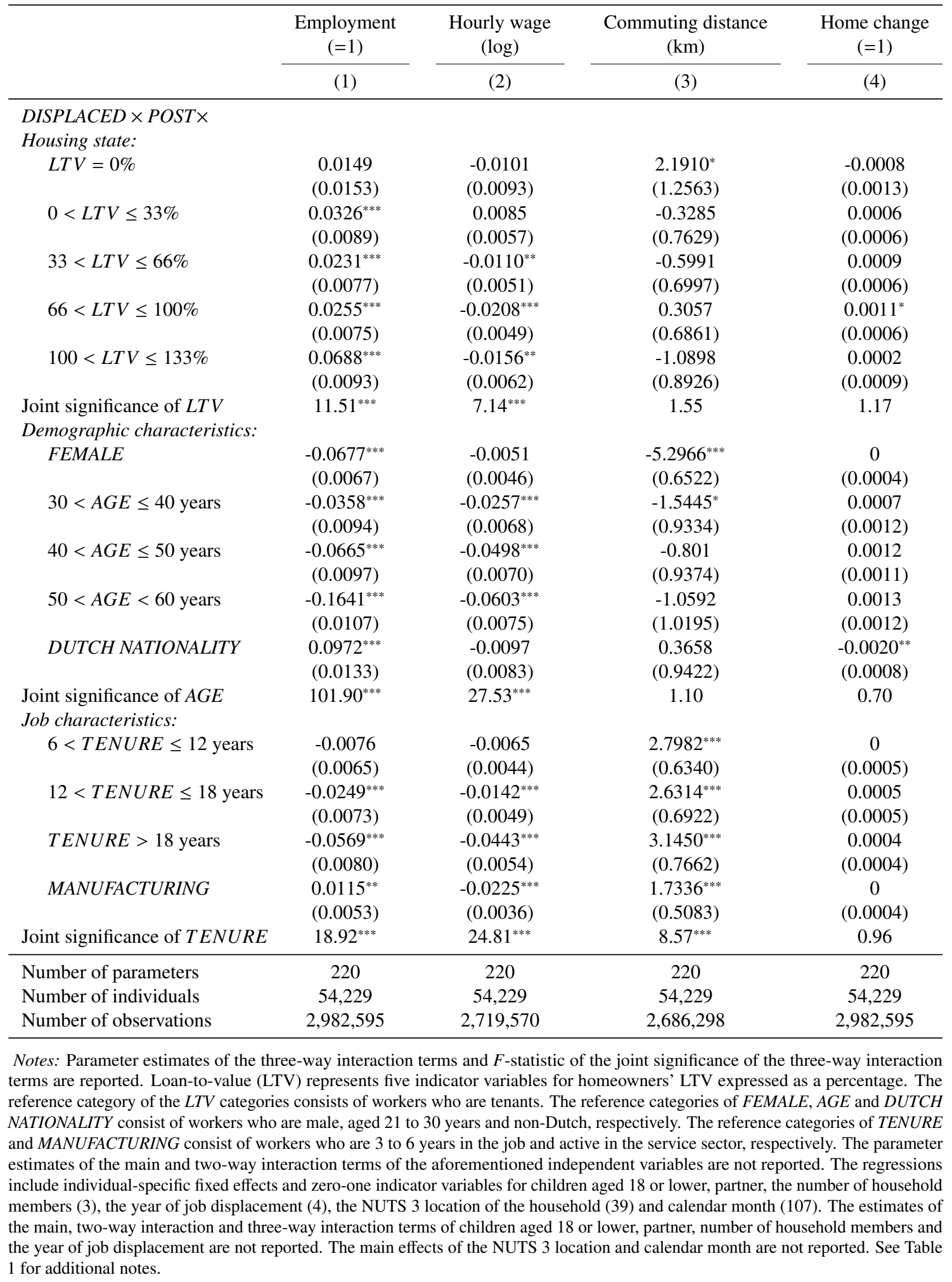

knowledge, this paper is the first to demonstrate the importance of workers' housing state for the post-displacement losses in employment and hourly wage.

Column (3) shows that various worker characteristics lead to a difference in the displacement effect on the commuting distance. Although displaced owners, compared with displaced tenants, do not experience a highly different displacement effect on commute, there is a significant difference within the group of displaced owners. Specifically, displaced outright owners expe- rience an increase of about 3 kilometres in commute higher than underwater owners. However, note that the three-way interaction terms for workers' housing state on commute are jointly insignificant. In addition, displaced women experience a significantly lower increase in the commuting distance than men. Moreover, the parameter estimates indicate that displaced workers who are high-tenured and active in the manufacturing sectors experience a relatively high increase in commute.

The parameter estimates in Column (4) show that the displace- 

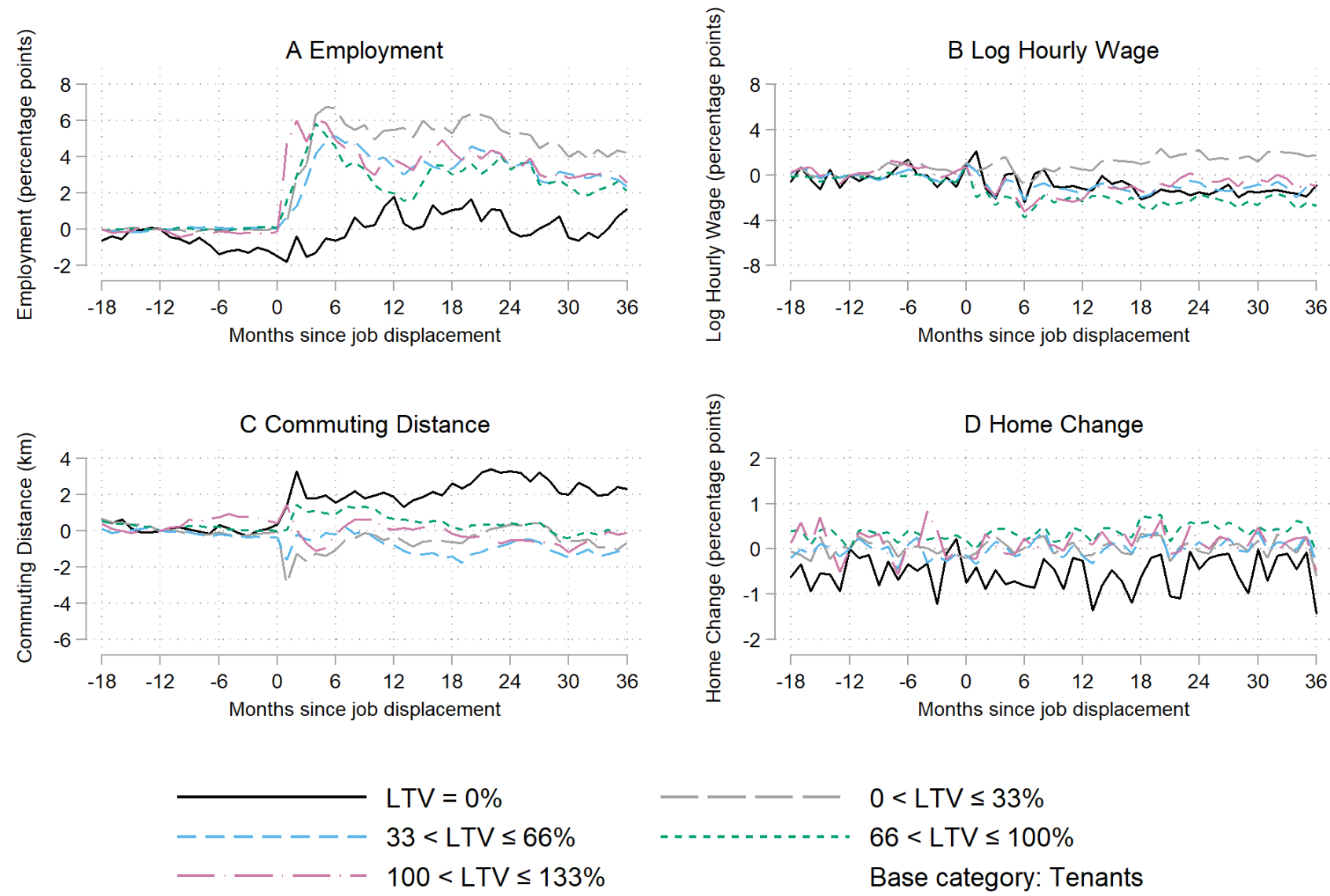

Fig. 3. Housing state differential in the time-dependent displacement effects (Eq. (4)). Notes: All four fixed effects regression models include 2,763 parameters. See Figure 1 for additional notes and Table 2 for additional statistics.

ment effect on changing home does not vary greatly in worker characteristics. For example, housing state seems to have no role in the displacement effect on changing home. The finding that the displacement effect on changing home does not differ between tenants and homeowners, could be explained by the fact that Dutch tenants typically are in social rental housing. Although social tenants have generally lower transaction costs of changing home than homeowners, rent control and the waiting list for social rental housing reduce home changes (Munch and Svarer, 2002, Kattenberg and Hassink, 2017). In addition, the estimates suggest that for underwater owners, job displacement does not function as a trigger of default. In the housing literature, the double trigger theory of default predicts that households are likely to experience a default and change home if two conditions are met: (i) the household is underwater and (ii) the household experiences an additional shock that prompts a relocation to a different home (Foote et al. 2008). In the context of our paper, job displacement could be considered as the potential second trigger that prompts a move out of the house. However, we do not find evidence of this mechanism. Our finding is in contrast with the studies of Niu and Ding (2015); Bricker and Bucks (2016), who show that job loss increases the foreclosure rate in the U.S., especially for workers with negative home equity. The disparity between the findings can be explained by the different institutional setting, as in the Netherlands the share of housing going into default and foreclosure is relatively low. A main reason for the low rate of default is, among others, the fact that all mortgage loans are full recourse loans.

We illustrate in Figure 3 the time-dependent differences in the importance of workers' housing state for the displacement effects (see Eq. (4)). ${ }^{22}$ We observe parallel pre-displacement trends in the outcome variables except for changing home. The pre-displacement trend in changing home is fairly stable given the low number of workers who change home (see Table C.3. Importantly, for each of the four margins of adjustment, the $F$-statistic on the joint significance of the eighteen pre-displacement three-way interaction terms is statistically insignificant. These results are available upon request.

Figure 3A shows that displaced tenants and outright owners experience a higher loss in employment than other displaced homeowners. This difference is relatively stable over the postdisplacement period. Figure 3B illustrates that displaced workers who have an LTV between 0 per cent and 33 per cent experience a relatively low loss in wage. Figure $3 \mathrm{C}$ indicates that

\footnotetext{
${ }^{22}$ See Figures E.1-E.6 in Appendix E for a comprehensive overview of the time-dependent differences in the importance of demographic and job characteristics for the displacement effects.
} 
outright owners experience a relatively high increase in the commuting distance. We do not find significant differences in the displacement effect on changing home for workers who vary in housing state (see Figure 3D). All in all, the results indicate that the importance of workers' housing state for displacement effects on employment, wages and commute is relatively persistent over the period since displacement. The displacement effects by workers' housing state suggest that workers who are displaced choose among adjustment at the employment, wage and commuting margins. In this regard, we argue that these margins of adjustment, next to endogenous search (Morescalchi 2016), are key to explaining the role of workers' housing state in employment outcomes.

\section{Conclusion}

The Great Recession that started in 2008 resulted in strong negative developments in the Dutch housing market and labour market. In this paper, we have examined workers' resilience to job displacement by focusing on the use of margins of adjustment that are related to space and the importance of workers' housing state. We used Dutch administrative monthly data of the period from January 2006 to December 2014, which were analysed with a quasi-experimental design involving job displacement that eliminates selection into labour turnover. Our conclusions are twofold.

First, we conclude that the spatial structure of homes and jobs reflects relevant margins of adjustment in response to job displacement. Our novel finding is that displaced workers experience an average increase of about 20 per cent in commuting distance and a decrease of about 14 per cent in changing home over the post-displacement period of thirty-six months. The results indicate that for workers who have been displaced the commuting distance is a more relevant margin of labour adjustment than changing home. Interestingly, the patterns of adjustment change over the worker's post-displacement period - a longer post-displacement unemployment duration is associated with a lower loss in employment, a smaller increase in commute, and a higher loss in hourly wage. We showed that the patterns in wage and commute are caused by displaced workers who take up their first job since displacement and not by displaced workers who change between jobs or homes. Consistent with a conceptual framework that predicts a positive correlation between wages and commute, our results suggest that displaced workers who experience a longer time of unemployment prefer a smaller increase in the commuting distance to a lower loss in hourly wage. Thus there are societal costs involved in job displacement, in addition to losses in employment and wages, due to an increase in the commuting distance. Our findings are relevant for policies that aim to limit the impact of negative employment shocks.

Second, we conclude that the worker's housing state is a substantial and persistent source of heterogeneity in the displacement effects on employment, wages and commute, but not on changing home. We find that displaced underwater homeowners, compared to other displaced owners and tenants, experience a lower loss in employment. Moreover, highly leveraged owners experience a relatively high loss in wage and become employed relatively close to home. In addition, outright owners experience the highest increase in the commuting distance. The results suggest that more leveraged workers have a stronger incentive to become employed. Moreover, it seems that the geographic immobility of displaced homeowners (relative to tenants) and underwater owners (relative to other owners) does not hinder post-displacement employment outcomes. The geographic immobility of Dutch workers could be relatively unimportant for the functioning of the labour market, as the surface area of the Netherlands is relatively small. In addition, the Great Recession led to a decrease in the overall propensity to change home, which could explain the negligible displacement effect on changing home throughout this period. Further research is needed to understand whether this observation also holds for other countries. Importantly, our findings are relevant for government policies that subsidise homeownership or stimulate mortgage debt, as relatively high mortgage debt does neither seem to hamper the labour market outcomes nor the probability of changing home following job displacement.

All in all, we showed that workers' housing state affects the post-displacement outcomes in employment, wage and commuting distance, but not in changing home. Consistent with financial incentive structures, this evidence suggests that more leveraged displaced owners prioritise sooner re-employment over lower wage losses. In this regard, endogenous job search intensity and efficiency alone does not fully explain the difference in the unemployment duration of workers who vary by housing state. Based on the evidence, however, we cannot discuss the extent to which displaced workers make trade-offs between the use of margins of adjustment. Further research, based on a structural approach, is needed to better understand this issue.

\section{Acknowledgements}

Thanks to seminar participants at the 21st IZA Summer School in Labor Economics, Melbourne Institute of Applied Economic and Social Research, Free University Amsterdam Department of Spatial Economics, IAAEU Workshop on Labour Economics 2017, RES PhD Meetings 2017, MIT Sloan School of Management ESWG, 11th Meeting of the Urban Economics Association, 28th European Association of Labour Economists Conference, Urban Economic Association Doctoral Summer School, CPB Netherlands Bureau for Economic Policy Analysis, and Utrecht University School of Economics. We wish to thank Stuart Rosenthal and two anonymous reviewers whose valuable comments substantially improved the quality of the paper. We also thank Bram van Besouw, Roberto Fernandez, Maarten Goos, Thomas van Huizen, Zornitza Kambourova, Mark Kattenberg, Bastian Ravesteijn, Vincent Schippers, Ahmad-Reza Sharifi and Coen Teulings for their insightful comments. We are grateful to Statistics Netherlands for giving us access to the administrative data.

\section{References}

Addison, J. T., Portugal, P., 1987. The effect of advance notification of plant closings on unemployment. Industrial and Labor Relations Review 41 (1), $3-16$. 
Andersson, F., Mayock, T., 2014. How does home equity affect mobility? Journal of Urban Economics 84, 23-39.

Baert, S., Heylen, F., Isebaert, D., 2014. Does homeownership lead to longer unemployment spells? The role of mortgage payments. De Economist 162 (3), 263-286.

Battu, H., Ma, A., Phimister, E., 2008. Housing tenure, job mobility and unemployment in the UK. The Economic Journal 118 (527), 311-328.

Bertrand, M., Duflo, E., Mullainathan, S., 2004. How much should we trust differences-in-differences estimates? The Quarterly Journal of Economics 119 (1), 249-275.

Bover, O., Arellano, M., Bentolila, S., 2002. Unemployment duration, benefit duration and the business cycle. The Economic Journal 112 (479), 223-265.

Bowles, S., 1970. Migration as investment: Empirical tests of the human investment approach to geographical mobility. Review of Economics and Statistics 52 (4), 356-362.

Bricker, J., Bucks, B., 2016. Negative home equity, economic insecurity, and household mobility over the Great Recession. Journal of Urban Economics 91, 1-12.

Brown, J., Matsa, D. A., 2017. Locked in by leverage: Job search during the housing crisis. SSRN Scholarly Paper ID 2880784, Social Science Research Network, Rochester, NY.

Brueckner, J. K., Thisse, J.-F., Zenou, Y., 2002. Local labor markets, job matching, and urban location. International Economic Review 43 (1), 155-171.

Caliendo, M., Gielen, A. C., Mahlstedt, R., 2015. Home-ownership, unemployed's job search behavior and post-unemployment outcomes. Economics Letters 137, 218-221.

Caliendo, M., Kopeinig, S., 2008. Some practical guidance for the implementation of propensity score matching. Journal of Economic Surveys 22 (1), 31-72.

Carrington, W. J., 1993. Wage losses for displaced workers: Is it really the firm that matters? Journal of Human Resources 28 (3), 435-462.

Carrington, W. J., Zaman, A., 1994. Interindustry variation in the costs of job displacement. Journal of Labor Economics 12 (2), 243-275.

CBS, 2018. CBS statline, Centraal Bureau voor de Statistiek, Den Haag/Heerlen.

Chan, S., 2001. Spatial lock-in: Do falling house prices constrain residential mobility? Journal of Urban Economics 49 (3), 567-586.

Chan, S., Stevens, A. H., 1999. Employment and retirement following a latecareer job loss. American Economic Review: Papers and Proceedings 89 (2), 211-216.

Chan, S., Stevens, A. H., 2001. Job loss and employment patterns of older workers. Journal of Labor Economics 19 (2), 484-521.

Couch, K. A., Placzek, D. W., 2010. Earnings losses of displaced workers revisited. American Economic Review 100 (1), 572-589.

Coulson, N. E., Fisher, L. M., 2002. Tenure choice and labour market outcomes Housing Studies 17 (1), 35-49.

Coulson, N. E., Grieco, P. L. E., 2013. Mobility and mortgages: Evidence from the PSID. Regional Science and Urban Economics 43 (1), 1-7.

Crépon, B., Van den Berg, G. J., 2016. Active labor market policies. Annual Review of Economics 8 (1), 521-546.

Deelen, A., De Graaf-Zijl, M., Van den Berge, W., 2014. Labour market effects of job displacement for prime-age and older workers. CPB Discussion Paper 285

Demyanyk, Y., Hryshko, D., Luengo-Prado, M. J., Sørensen, B. E., 2017. Moving to a job: The role of home equity, debt, and access to credit. American Economic Journal: Macroeconomics 9 (2), 149-181.

DiPasquale, D., Glaeser, E. L., 1999. Incentives and social capital: Are homeowners better citizens? Journal of Urban Economics 45 (2), 354-384.

DiPasquale, D., Wheaton, W. C., 1996. Urban economics and real estate markets. Englewood Cliffs, NJ : Prentice Hall.

Eliason, M., Storrie, D., 2006. Lasting or latent scars? Swedish evidence on the long-term effects of job displacement. Journal of Labor Economics 24 (4), $831-856$.

Farber, H. S., 1999. Chapter 37 - Mobility and stability: The dynamics of job change in labor markets. In: Ashenfelter, O. C., Card, D. (Eds.), Handbook of Labor Economics. Vol. III. Elsevier, pp. 2439-2483.

Farber, H. S., 2017. Employment, hours, and earnings consequences of job loss: US evidence from the displaced workers survey. Journal of Labor Economics 35 (S1), S235-S272.

Farber, H. S., Hall, R., Pencavel, J., 1993. The incidence and costs of job loss: 1982-91. Brookings Papers on Economic Activity. Microeconomics 1993 (1), $73-132$.
Fernandez, R. M., Su, C., 2004. Space in the study of labor markets. Annual Review of Sociology 30 (1), 545-569.

Ferreira, F., Gyourko, J., Tracy, J., 2010. Housing busts and household mobility. Journal of Urban Economics 68 (1), 34-45.

Flatau, P., Forbes, M., Hendershott, P. H., Wood, G., 2003. Homeownership and unemployment: The roles of leverage and public housing. NBER Working Paper 10021

Foote, C. L., Gerardi, K., Willen, P. S., 2008. Negative equity and foreclosure: Theory and evidence. Journal of Urban Economics 64 (2), 234-245.

Frederiksen, A., Ibsen, R., Rosholm, M., Westergaard-Nielsen, N., 2013. Labour market signalling and unemployment duration: An empirical analysis using employer-employee data. Economics Letters 118 (1), 84-86.

Genesove, D., Mayer, C., 2001. Loss aversion and seller behavior: Evidence from the housing market. The Quarterly Journal of Economics 116 (4), 1233 1260.

Ghent, A. C., Kudlyak, M., 2011. Recourse and residential mortgage default: Evidence from US states. Review of Financial Studies 24 (9), 3139-3186.

Gibbons, R., Katz, L. F., 1991. Layoffs and lemons. Journal of Labor Economics 9 (4), 351-380.

Goss, E. P., Phillips, J. M., 1997. The impact of home ownership on the duration of unemployment. Review of Regional Studies 27 (1), 9-27.

Hamermesh, D. S., 1987. The costs of worker displacement. The Quarterly Journal of Economics 102 (1), 51-75.

Hardoy, I., Schøne, P., 2014. Does the impact of plant closure on labour market attachment differ between immigrants and native workers across the business cycle? Empirical Economics 46 (1), 229-252.

Head, A., Lloyd-Ellis, H., 2012. Housing liquidity, mobility and the labour market. Review of Economic Studies 79, 1559-1589.

Heckman, J. J., Ichimura, H., Smith, J., Todd, P., 1998. Characterizing selection bias using experimental data. Econometrica 66 (5), 1017-1098.

Heckman, J. J., Ichimura, H., Todd, P. E., 1997. Matching as an econometric evaluation estimator: Evidence from evaluating a job training programme. Review of Economic Studies 64 (4), 605-654.

Heckman, J. J., Smith, J. A., 1999. The pre-programme earnings dip and the determinants of participation in a social programme. Implications for simple programme evaluation strategies. The Economic Journal 109 (457), 313-348.

Hellerstein, J. K., Kutzbach, M. J., Neumark, D., 2016. Labor market networks and recovery from mass layoffs before, during, and after the Great Recession. IZA Discussion Paper 9852.

Henley, A., Disney, R., Carruth, A., 1994. Job tenure and asset holdings. The Economic Journal 104 (423), 338-349.

Hijzen, A., Upward, R., Wright, P. W., 2010. The income losses of displaced workers. Journal of Human Resources 45 (1), 243-269.

Hu, L., Taber, C., 2011. Displacement, asymmetric information, and heterogeneous human capital. Journal of Labor Economics 29 (1), 113-152.

Huttunen, K., Møen, J., Salvanes, K. G., 2011. How destructive is creative destruction? Effects of job loss on job mobility, withdrawal and income Journal of the European Economic Association 9 (5), 840-870.

Huttunen, K., Møen, J., Salvanes, K. G., 2018. Job loss and regional mobility. Journal of Labor Economics 36 (2), 479-509.

Iacus, S. M., King, G., Porro, G., 2011. Multivariate matching methods that are monotonic imbalance bounding. Journal of the American Statistical Association 106 (493), 345-361.

Ichino, A., Schwerdt, G., Winter-Ebmer, R., Zweimüller, J., 2017. Too old to work, too young to retire? Journal of the Economics of Ageing 9, 14-29.

Jacobson, L. S., LaLonde, R. J., Sullivan, D. G., 1993. Earnings losses of displaced workers. American Economic Review 83 (4), 685-709.

Kattenberg, M. A. C., Hassink, W. H. J., 2017. Who moves out of social housing? The effect of rent control on housing tenure choice. De Economist 165 (1), 43-66.

Katz, L. F., Meyer, B. D., 1990. The impact of the potential duration of unemployment benefits on the duration of unemployment. Journal of Public Economics 41 (1), 45-72.

Kothari, S., Saporta-Eksten, I., Yu, E., 2013. The (un)importance of geographical mobility in the Great Recession. Review of Economic Dynamics 16 (3), 553 563.

Krolikowski, P., 2017. Choosing a control group for displaced workers. ILR Review, 1-23.

Kuhn, P., 2002. Losing work, moving on: International perspectives on worker displacement. W.E. Upjohn Institute for Employment Research, Kalamazoo, MI. 
Madden, J. F., 1987. Gender differences in the cost of displacement: An empirical test of discrimination in the labor market. American Economic Review: Papers and Proceedings 77 (2), 246-251.

Manning, A., 2003. The real thin theory: Monopsony in modern labour markets. Labour Economics 10 (2), 105-131.

Mayock, T., 2015. Wages, housing prices and commutes. Real Estate Economics 44 (1), 258-300.

Meekes, J., 2019. Local labour markets, job displacement and agglomeration economies. Ph.D. thesis, Utrecht University, Utrecht.

Meekes, J., Hassink, W. H. J., 2018. The role of the housing market in workers' resilience to job displacement after firm bankruptcy. Journal of Urban Economics, In Press.https ://doi.org/10.1016/j.jue.2018.11.005

Modestino, A. S., Dennett, J., 2013. Are American homeowners locked into their houses? The impact of housing market conditions on state-to-state migration. Regional Science and Urban Economics 43 (2), 322-337.

Morescalchi, A., 2016. The puzzle of job search and housing tenure: A reconciliation of theory and empirical evidence. Journal of Regional Science 56 (2), 288-312.

Moriizumi, Y., Naoi, M., 2011. Unemployment risk and the timing of homeownership in Japan. Regional Science and Urban Economics 41 (3), 227-235.

Mulalic, I., Van Ommeren, J., Pilegaard, N., 2014. Wages and commuting: Quasi-natural experiments' evidence from firms that relocate. The Economic Journal 124 (579), 1086-1105.

Munch, J. R., Rosholm, M., Svarer, M., 2006. Are homeowners really more unemployed? The Economic Journal 116 (514), 991-1013.

Munch, J. R., Rosholm, M., Svarer, M., 2008. Home ownership, job duration, and wages. Journal of Urban Economics 63 (1), 130-145.

Munch, J. R., Svarer, M., 2002. Rent control and tenancy duration. Journal of Urban Economics 52 (3), 542-560.

Niu, Y., Ding, C., 2015. Unemployment matters: Improved measures of labor market distress in mortgage default analysis. Regional Science and Urban Economics 52, 27-38.

Nord, S., Ting, Y., 1991. The impact of advance notice of plant closings on earnings and the probability of unemployment. Industrial and Labor Relations Review 44 (4), 681-691.

OECD, 2010. General assessment of the macroeconomic situation. In: OECD Economic Outlook. Vol. 1 of 2010. OECD Publishing, pp. 11-71.

Rubin, D. B., 2006. Matched sampling for causal effects. Cambridge University Press, Cambridge, UK.

Schwerdt, G., 2011. Labor turnover before plant closure: "Leaving the sinking ship" vs. "Captain throwing ballast overboard". Labour Economics 18 (1), 93-101.

Simpson, W., Van der Veen, A., 1992. The economics of commuting and the urban labour market. Journal of Economic Surveys 6 (1), 45-62.

Smith, T. E., Zenou, Y., 1997. Dual labor markets, urban unemployment, and multicentric cities. Journal of Economic Theory 76 (1), 185-214.

Smith, T. E., Zenou, Y., 2003. Spatial mismatch, search effort, and urban spatial structure. Journal of Urban Economics 54 (1), 129-156.

Steegmans, J., Hassink, W. H. J., 2018. Decreasing house prices and household mobility: An empirical study on loss aversion and negative equity. Journal of Regional Science 58 (3), 611-634.

Stein, J. C., 1995. Prices and trading volume in the housing market: A model with down-payment effects. The Quarterly Journal of Economics 110 (2), 379-406.

Stevens, A. H., 1997. Persistent effects of job displacement: The importance of multiple job losses. Journal of Labor Economics 15 (1), 165-188.

Tatsiramos, K., 2010. Job displacement and the transitions to re-employment and early retirement for non-employed older workers. European Economic Review 54 (4), 517-535.

Topel, R., 1990. Specific capital and unemployment: Measuring the costs and consequences of job loss. Carnegie-Rochester Conference Series on Public Policy 33, 181-214.

Valletta, R. G., 2013. House lock and structural unemployment. Labour Economics 25 (C), 86-97.

Van Leuvensteijn, M., Koning, P., 2004. The effect of home-ownership on labor mobility in the Netherlands. Journal of Urban Economics 55 (3), 580-596.

Van Ommeren, J., Fosgerau, M., 2009. Workers' marginal costs of commuting. Journal of Urban Economics 65 (1), 38-47.

Van Ommeren, J., Rietveld, P., 2005. The commuting time paradox. Journal of Urban Economics 58 (3), 437-454.

Van Ommeren, J., Van Den Berg, G. J., Gorter, C., 2000. Estimating the marginal willingness to pay for commuting. Journal of Regional Science 40 (3), 541563.

Von Wachter, T., Bender, S., 2006. In the right place at the wrong time: The role of firms and luck in young workers' careers. American Economic Review 96 (5), 1679-1705.

Zax, J. S., 1991. Compensation for commutes in labor and housing markets. Journal of Urban Economics 30 (2), 192-207. 


\section{Appendix A Data Construction and Sample Selections}

All individuals, firms and household addresses were uniquely identified on the basis of an encrypted Randomised Identification Number (RIN). We used the data set Bankruptcy Job Endings Register (Failontslagtab), which records the worker's RIN, the job's RIN and the date the firm entity is declared bankrupt for individuals who had a job at a firm where at least one entity of the firm experiences bankruptcy. Consequently, we possibly incorporated the so-called false-positives, i.e. we labelled voluntary job terminations in the bankrupted or non-bankrupted entity of a firm as a displacement due to firm bankruptcy. To limit the scope of false-positives we applied various data selections, which are discussed below.

Jobs that ended in year $t$ or $t+1$ surrounding a bankruptcy of a firm entity were registered in the Bankruptcy Job Endings Register. The time span of year $t$ to $t+1$ was chosen as jobs are recorded from firm payrolls that can continue after the verdict of bankruptcy. We selected workers for the group of displaced workers if the date of the job ending was earlier than one year after the date of bankruptcy or later than six months prior to the date of bankruptcy. This restriction ensured that the early leavers, who may have anticipated the plant closure, were incorporated in the analysis (see Schwerdt, 2011).

The Bankruptcy Job Endings Register was combined with multiple other registers. The Job Register (Baankenmerkenbus) was used to incorporate the date of job openings, the date of job endings and the RIN of the firm in which the worker was an employee. The Main Job Register (Hfdbaanbus) was used to distinguish between the main job and secondary job of an individual. The worker's main job, observed on a monthly basis, is the job with the highest wage. The Job and Wages Register (Polisbus) records monthly data based on income statements of employees to the tax office administration, including type of job (full-time or part-time), type of contract (fixed or temporary), number of hours worked and gross wage. The data set Work Location Register (Gemstplbus) was used to incorporate data on the municipality in which the worker was employed. ${ }^{23}$ The number of municipalities changed over the period under observation as various municipalities were aggregated. We used the set of 403 municipalities that existed in the year 2014. The Firm Register (Betab) was used to incorporate annual data on firm size and firm sector. Firm sectors were classified in 21 sectors according to a five-digit code (in Dutch: Standaard Bedrijfs Indeling), which is based on the International Standard Industrial Classification

\footnotetext{
${ }^{23}$ Work location is not complete nor consistent as the CBS has only data that is measured in December on the number of plants of a firm, the location of each firm plant and the number of employees at each specific plant. Work location is imputed by the CBS using data on the location of the workplace and residential home. Each resident is linked to the closest plant of a firm, conditional on not exceeding the number of workers employed at that specific plant. Hence, we do not observe the work location of workers if they were not in the job in December. We assessed the consequences of the incompleteness and inconsistency of the variable work location by applying two robustness checks. First, we excluded all workers whose firm location is not completely observed for all jobs in the period 2006 to 2014 (see Table D.1). Second, we ran a robustness check with firms that consist of 49 employees at maximum to ensure a low number of firm plants (see Table D.2). We find similar results.
}

of All Economic Activities (ISIC). The extraterritorial organisations and bodies sector was excluded as no displaced worker was employed in this sector.

Registers that are based on municipal and tax office administration were used to incorporate personal, home and household information. The Population Register (Gbapersoontab, Gbahuishoudensbus, Gbaburgerlijkestaatbus, Gbaadresgebeurtenisbus) contains monthly data on the date of birth, gender, marital status, number of household members and changing home. The Address Object Register (Gbaadresobjectbus, Vslgwbtab) contains data on individuals' house address and home location at the neighbourhood level. The Highest Education Register (Hoogsteopltab) was used and contains data on workers' highest level of attained education. Education is categorised in lower, secondary and tertiary education based on the International Standard Classification of Education (ISCED). The Integrated Household Income data set (Integraal Huishoudens Inkomen), which is based on data measured on the 31st of December retrieved from the tax office, was used to incorporate data on housing state and household income. In the case of changing home, data on housing state was used from the year prior to that of changing. As an example, for household relocations to different homes in 2006 we used data from 2005. The Integrated Capital data set (Integraal-Vermogensbestand), which consists of annual records from the tax office measured on the 1 st of January, was used to incorporate data on the mortgage debt, non-housing wealth and property value of the home. In the case of changing home during the year, data on the mortgage debt and property value were used from the year after the home change. As an example, for household relocations in 2014 we used data from the year 2015.

The following selections were made to attain an appropriate sample for our analysis. To keep the employment history of a worker tractable, all job spells that were not identified as the main job were excluded. Moreover, we excluded groups of individuals for various reasons. First, we excluded all individuals who were not active in the labour market (e.g., disabled individuals, students and early retirees), who had no administered employment history (e.g., self-employed and long-term unemployed), or were aged below 21 or over 60 years. Second, our data do not distinguish between a bankrupt or restarted firm. Hence, we excluded workers from the group of displaced workers if more than 40 per cent of the displaced workers who were employed at the bankrupt firm became re-employed at another but identical firm. Third, all workers who had ever an LTV over 133 per cent during the period under observation were excluded from the sample, as a higher LTV suggests an administrative error. Finally, all workers with three or more home changes in one calendar year were excluded from the sample, as this would create the problem that we could not observe data on all homes. We kept individuals that experienced two home changes in one year, as on many occasions households change home to one temporary accommodation following the sale of their home.

Prior to Coarsened Exact Matching, individuals were excluded from the group of displaced or non-displaced for various reasons. First, we excluded all workers whose hourly wage or housing state was not completely observed for all jobs and homes in the 
period 2006 to 2014. In multiple cases this was possible, as we did not perfectly link all the information of the Job Register to the Job and Wages Register and the Housing registers. In addition, we excluded individuals whose hourly wage is equal to or lower than one euro. Second, we excluded all workers with an employment spell shorter than three years. An employment spell of at least three years allows us to incorporate workers who had a stable job and who experienced an unexpected and involuntary job displacement. Thereby, the likelihood of falsepositives was reduced. Third, we excluded all workers who, in the month prior to job displacement, worked at a firm with less than ten employees or who worked less than 64 hours in that month. Finally, we had to randomly exclude about 70 per cent of the non-displaced workers (controls) due to computational limitations.

After the process of matching, if the displaced or nondisplaced worker of a matched pair was not under observation for the entire period of fifty-five months, the matched pair was excluded. The matched pairs were excluded as the incomplete data imply data gaps due to, e.g., immigration, emigration or death. This selection ensured a weakly balanced sample. Only 35 individual workers, which represents about 0.23 per cent of the full sample, were not observed for the entire period. In total, 123 workers were excluded.

\section{Appendix B Robustness Checks for the Empirical Models on Worker Characteristics}

As discussed in Section 4, we created a new matched sample for each of the three robustness checks. The matched samples for each robustness check were created based on a different set of matching variables, which included indicator variables for the non-housing wealth position and duration of home occupancy, LTI ratio, and skill level, respectively.

First, we assess whether the estimates of the interaction terms between job displacement and LTV are robust to the inclusion of approximations of non-housing wealth and duration of home occupancy. The non-housing wealth position of the displaced worker can be of importance for post-displacement outcomes, as it can aid job search through increased mobility or deter job search through decreased job search activity (Henley et al., 1994, Goss and Phillips, 1997). The duration of home occupancy approximates the willingness to change home and is, consequently, an important driver behind the ability to become employed in a distant labour market. Moreover, we capture further unobserved heterogeneity in human capital by controlling for non-housing wealth and duration of home occupancy. Human capital is expected to be positively correlated to non-housing wealth and negatively correlated to duration of home occupancy, as high-skilled workers earn a relatively high income and are characterised by a relatively high geographical mobility (e.g., Bowles, 1970).

The non-housing wealth is represented by five zero-one indicator variables that equal one for non-housing household wealth below 0 (base category), between 0-5,000; 5,000-25,000; 25,00075,000 and over 75,000 euro, respectively. The duration of home occupancy is represented by three zero-one indicator variables that equal one if the period in the home equals 0-60 (base category), 60-180 and over 180 months, respectively.

Table B.1 shows the role of workers' housing state, nonhousing wealth and duration of home occupancy in the displacement effects on the margins of adjustment. The estimates indicate that workers who have positive non-housing wealth experience a relatively low loss in employment. The results suggest that the loss in employment is decreasing and the loss in wage is increasing in workers' LTV. This result supports the results of the model in which we do not control for non-housing wealth and duration of home occupancy (See Table 2). Note that by simultaneously controlling for housing state, non-housing wealth and duration of home occupancy, the fixed effects coefficients of the two highest LTV categories on hourly wage become slightly higher. Also, the role of housing state in the displacement effect on commuting distance is more pronounced. Compared with displaced underwater owners, displaced outright owners experience an increase in the commuting distance of about 7 kilometres higher.

Second, we assess whether our results are robust to the inclusion of the LTI ratio as an additional approximation of the financial incentive to work. The LTI ratio is constructed by the mortgage loan of year $t$ relative to the gross household income of year $t-1$, where year $t$ is the year of job displacement. The LTI ratio is time-invariant, to prevent the situation that a large share of variation in the LTI ratio is caused by changes in household income following job displacement. The LTI ratio is operated as five zero-one indicator variables, which equal one if the LTI ratio ranges between 0-1.5 (base category), 1.5-3.0, 3.0-4.5, 4.5-6.0 and over 6.0, respectively.

Table B. 2 shows the role of workers' housing state and LTI ratio in the displacement effects. We find that the fixed effects coefficients of the LTV on wage become higher if we include variables that represent the LTI ratio. However, the fixed effects coefficients of the LTV on employment become smaller and less significant. Compared with displaced workers who have an LTI ratio between 0 to 1.5 , displaced workers with an LTI ratio over 6.0 experience a lower loss in the hourly wage. Note, however, that the results in Table B.2 are relatively sensitive, as the categorical variables $L T V$ and $L T I$ ratio are highly correlated, i.e. a correlation equal to 0.88 .

Third, we assess whether our results are robust to the inclusion of the worker's skill level. The impact of skill on the post-displacement losses is theoretically ambiguous. On the one hand, high-skilled workers have a higher job offer arrival rate. The higher job offer arrival rate is driven by the higher willingness to commute and relocate (Zax, 1991). Consequently, the distribution of job offers is increasing in the skill level of the displaced worker. Moreover, the market power of employers is decreasing in the skill level of the displaced worker. Hence, the losses in employment and wages for high-skilled displaced workers are likely to be relatively low. On the other hand, highskilled workers have a relatively high wage premium due to their firm-specific human capital. If high-skilled workers invested more in human capital than low-skilled workers, the displacement effect on wage would be higher for high-skilled workers. Hijzen et al. (2010) show that high skilled workers have higher 
Table B1

The role of housing state, non-housing wealth and duration of home occupancy in the displacement effects (Eq. (3)).

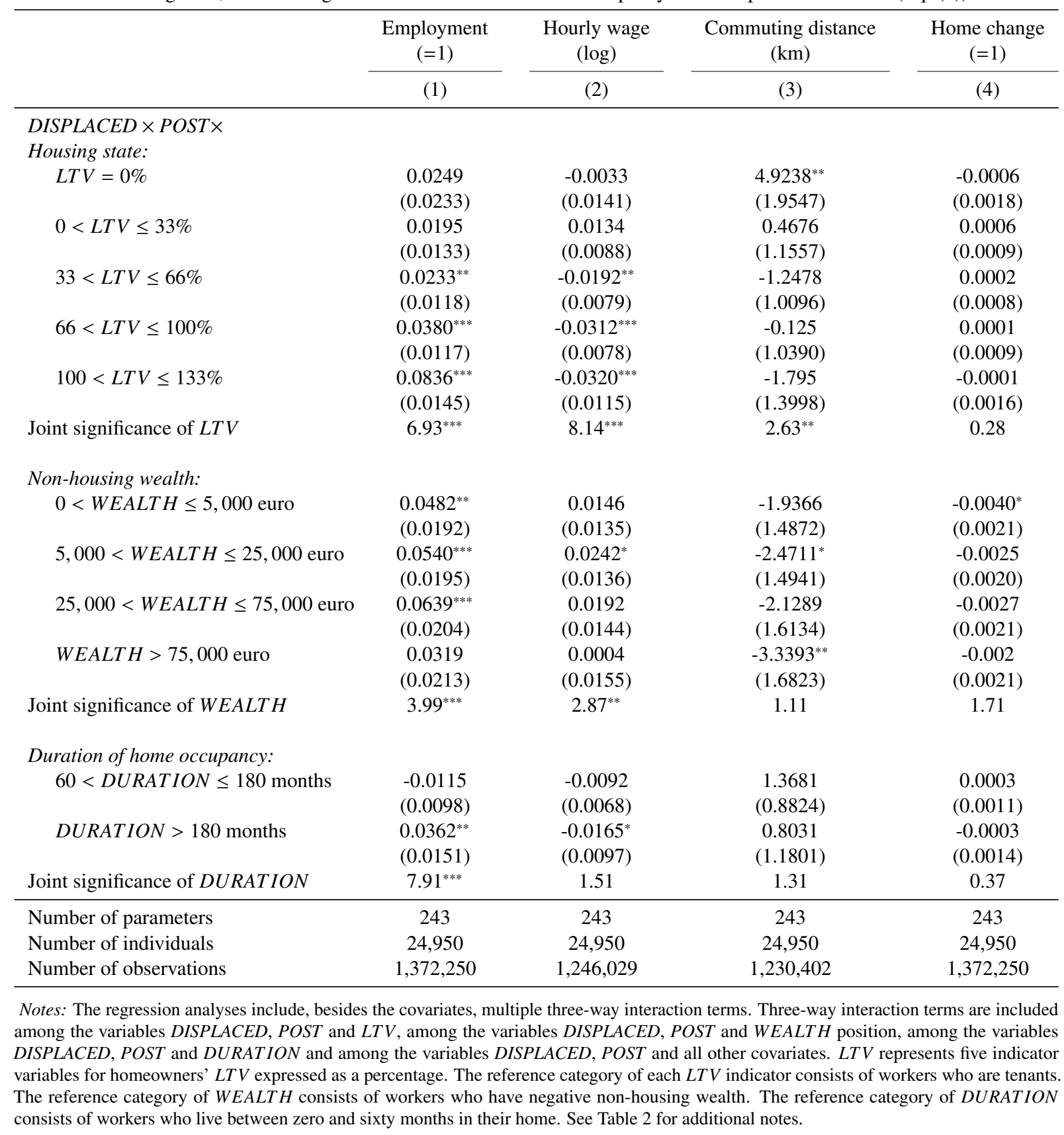

initial losses in wage than unskilled workers, but two years after job displacement the skill difference in wage losses becomes statistically insignificant. Farber (2017) shows that a higher number of years in education decreases the losses in employment and earnings.

The data we used on skill level is based on the international standard classification of education 1997, and is represented by three variables that equal one if the skill level is low (base category), medium, and high, respectively. We only incorporated the skill level in a robustness check, because the education data is highly selective as it is only available for individuals who received their diploma after the year 1995.
The fixed effects coefficients of LTV on employment that are shown in Table B.3 and Table B.4 are based on the sample in which we matched on the default set of matching variables and workers' skill level. The coefficients of the three-way interaction terms including the LTV without controlling for workers' skill level (see Table B.3) are similar to the coefficients of the model including covariates for workers' skill level (see Table B.4). Hence, we argue that the results are robust to the inclusion of variables that represent the skill level. Note, however, that compared to the parameter estimates provided in Table 2 of the model in which we do not match and control for the skill level, the coefficients shown in Table B.3 and Table B.4 are different. 
Table B2

The role of housing state and the loan-to-income ratio in the effects of job displacement (Eq. (3)).

\begin{tabular}{|c|c|c|c|c|}
\hline & $\begin{array}{l}\text { Employment } \\
\qquad(=1)\end{array}$ & $\begin{array}{l}\text { Hourly wage } \\
\qquad(\log )\end{array}$ & $\begin{array}{l}\text { Commuting distance } \\
\qquad(\mathrm{km})\end{array}$ & $\begin{array}{l}\text { Home change } \\
\qquad(=1)\end{array}$ \\
\hline & (1) & (2) & (3) & (4) \\
\hline \multicolumn{5}{|l|}{ DISPLACED $\times$ POST $\times$} \\
\hline \multicolumn{5}{|l|}{ Housing state: } \\
\hline \multirow[t]{2}{*}{$L T V=0 \%$} & 0.0182 & -0.0157 & 1.2188 & -0.0015 \\
\hline & $(0.0171)$ & $(0.0098)$ & $(1.4024)$ & $(0.0009)$ \\
\hline \multirow[t]{2}{*}{$0<L T V \leq 33 \%$} & $0.0462^{* * *}$ & -0.0058 & -0.8464 & -0.0005 \\
\hline & $(0.0109)$ & $(0.0070)$ & $(0.9083)$ & $(0.0005)$ \\
\hline \multirow[t]{2}{*}{$33<L T V \leq 66 \%$} & $0.0278^{*}$ & $-0.0313^{* * *}$ & 0.6234 & -0.0001 \\
\hline & $(0.0168)$ & $(0.0109)$ & $(1.4444)$ & $(0.0007)$ \\
\hline \multirow[t]{2}{*}{$66<L T V \leq 100 \%$} & 0.0181 & $-0.0499^{* * *}$ & 1.4075 & -0.0011 \\
\hline & $(0.0192)$ & $(0.0128)$ & $(1.7113)$ & $(0.0009)$ \\
\hline \multirow[t]{2}{*}{$100<L T V \leq 133 \%$} & 0.0318 & $-0.0436^{* * *}$ & 1.1386 & -0.0009 \\
\hline & $(0.0218)$ & $(0.0150)$ & $(2.0181)$ & $(0.0014)$ \\
\hline Joint significance of $L T V$ & $4.32^{* * *}$ & $3.85^{* * *}$ & 0.80 & 1.19 \\
\hline \multicolumn{5}{|l|}{ Loan-to-income: } \\
\hline \multirow[t]{2}{*}{$1.5<L T I \leq 3.0$} & 0.0096 & -0.0013 & -0.9248 & -0.0003 \\
\hline & $(0.0140)$ & $(0.0089)$ & $(1.1891)$ & $(0.0005)$ \\
\hline \multirow[t]{2}{*}{$3.0<L T I \leq 4.5$} & 0.0078 & 0.017 & $-2.8291^{*}$ & 0.0008 \\
\hline & $(0.0173)$ & $(0.0115)$ & $(1.5171)$ & $(0.0007)$ \\
\hline \multirow[t]{2}{*}{$4.5<L T I \leq 6.0$} & 0.028 & $0.0318^{* *}$ & -2.0954 & 0.0005 \\
\hline & $(0.0193)$ & $(0.0128)$ & $(1.7196)$ & $(0.0009)$ \\
\hline \multirow[t]{2}{*}{$L T I>6.0$} & 0.0243 & $0.0437^{* * *}$ & -1.9796 & 0.0011 \\
\hline & $(0.0202)$ & $(0.0136)$ & $(1.8190)$ & $(0.0011)$ \\
\hline Joint significance of $L T I$ & 0.99 & $4.62^{* * *}$ & 1.05 & 1.36 \\
\hline Number of parameters & 218 & 218 & 218 & 218 \\
\hline Number of individuals & 41,359 & 41,359 & 41,359 & 41,359 \\
\hline Number of observations & $2,274,745$ & $2,065,937$ & $2,040,254$ & $2,274,745$ \\
\hline
\end{tabular}

Notes: Parameter estimates of the three-way interaction terms among DISPLACED, POST and LTI, and among DISPLACED, POST and $L T I$ are displayed. The reference categories of $L T V$ and $L T I$ consist of workers who are tenants and who have an LTI ratio between 0 and 1.5 , respectively. The parameter estimates of the covariates and the two-way interaction terms are not reported. See Table 2 for additional notes.

Specifically, by matching on and controlling for housing state and skill level, the coefficients of the two highest LTV categories on hourly wage become smaller. Hence, Table B.3 and Table B.4 suggest that the difference in results is completely driven by the difference in sample, which can be explained by the fact that the education data is highly selective. 
Table B3

The role of housing state in the effects of job displacement, sample of Table B.4 (Eq. (3)).

\begin{tabular}{|c|c|c|c|c|}
\hline & $\begin{array}{l}\text { Employment } \\
\qquad(=1)\end{array}$ & $\begin{array}{l}\text { Hourly wage } \\
\text { (log) }\end{array}$ & $\begin{array}{l}\text { Commuting distance } \\
\qquad(\mathrm{km})\end{array}$ & $\begin{array}{l}\text { Home change } \\
\qquad(=1)\end{array}$ \\
\hline & (1) & (2) & (3) & (4) \\
\hline \multicolumn{5}{|l|}{$D I S P L A C E D \times P O S T \times$} \\
\hline \multicolumn{5}{|l|}{ Housing state: } \\
\hline \multirow[t]{2}{*}{$L T V=0 \%$} & -0.0092 & 0.0187 & 2.1841 & 0.0013 \\
\hline & $(0.0308)$ & $(0.0191)$ & $(2.8782)$ & $(0.0033)$ \\
\hline \multirow[t]{2}{*}{$0<L T V \leq 33 \%$} & 0.0137 & 0.0136 & 0.6967 & 0.0018 \\
\hline & $(0.0180)$ & $(0.0117)$ & $(1.4101)$ & $(0.0014)$ \\
\hline \multirow[t]{2}{*}{$33<L T V \leq 66 \%$} & 0.0007 & -0.0016 & -1.3845 & $0.0028^{* *}$ \\
\hline & $(0.0156)$ & $(0.0104)$ & $(1.4063)$ & $(0.0013)$ \\
\hline \multirow[t]{2}{*}{$66<L T V \leq 100 \%$} & 0.0068 & $-0.0211^{* *}$ & 0.5587 & 0.0011 \\
\hline & $(0.0147)$ & $(0.0096)$ & $(1.3440)$ & $(0.0013)$ \\
\hline \multirow[t]{2}{*}{$100<L T V \leq 133 \%$} & $0.0684^{* * *}$ & 0.0060 & -1.2052 & 0.0016 \\
\hline & $(0.0169)$ & $(0.0121)$ & $(1.6898)$ & $(0.0018)$ \\
\hline Joint significance of $L T V$ & $4.39^{* * *}$ & $2.65^{* *}$ & 0.84 & 1.23 \\
\hline Number of parameters & 219 & 219 & 219 & 219 \\
\hline Number of individuals & 14,028 & 14,028 & 14,028 & 14,028 \\
\hline Number of observations & 771,54 & 686,218 & 674,767 & 771,54 \\
\hline
\end{tabular}

Notes: The regression analyses include, besides the covariates, multiple three-way interaction terms. Three-way interaction terms are included among the variables DISPLACED, POST and LTV and among the variables DISPLACED, POST and all other covariates. See Table 2 for additional notes. 
Table B4

The role of housing state and skill level in the effects of job displacement (Eq. (3)).

\begin{tabular}{|c|c|c|c|c|}
\hline & $\begin{array}{l}\text { Employment } \\
\qquad(=1)\end{array}$ & $\begin{array}{l}\text { Hourly wage } \\
\text { (log) }\end{array}$ & $\begin{array}{l}\text { Commuting distance } \\
(\mathrm{km})\end{array}$ & $\begin{array}{l}\text { Home change } \\
\qquad(=1)\end{array}$ \\
\hline & (1) & (2) & (3) & (4) \\
\hline \multicolumn{5}{|l|}{ DISPLACED $\times P O S T \times$} \\
\hline \multicolumn{5}{|l|}{ Housing state: } \\
\hline \multirow[t]{2}{*}{$L T V=0 \%$} & -0.0105 & 0.0185 & 1.4114 & 0.0011 \\
\hline & $(0.0309)$ & $(0.0190)$ & $(2.9060)$ & $(0.0033)$ \\
\hline \multirow[t]{2}{*}{$0<L T V \leq 33 \%$} & 0.0120 & 0.0154 & 0.2910 & 0.0017 \\
\hline & $(0.0181)$ & $(0.0118)$ & $(1.4346)$ & $(0.0014)$ \\
\hline \multirow[t]{2}{*}{$33<L T V \leq 66 \%$} & -0.0007 & -0.0006 & -1.9666 & $0.0027^{* *}$ \\
\hline & $(0.0157)$ & $(0.0105)$ & $(1.4490)$ & $(0.0013)$ \\
\hline \multirow[t]{2}{*}{$66<L T V \leq 100 \%$} & 0.0090 & $-0.0207^{* *}$ & -0.4087 & 0.0009 \\
\hline & $(0.0150)$ & $(0.0099)$ & $(1.3951)$ & $(0.0014)$ \\
\hline \multirow[t]{2}{*}{$100<L T V \leq 133 \%$} & $0.0733^{* * *}$ & 0.0042 & -2.3556 & 0.0014 \\
\hline & $(0.0172)$ & $(0.0123)$ & $(1.7555)$ & $(0.0019)$ \\
\hline Joint significance of $L T V$ & $4.90^{* * *}$ & $2.61^{* *}$ & 1.01 & 1.14 \\
\hline \multicolumn{5}{|l|}{ Skill: } \\
\hline \multirow[t]{2}{*}{ MEDIUM S KILL } & 0.0175 & -0.0087 & 1.7206 & 0.0004 \\
\hline & $(0.0126)$ & $(0.0081)$ & $(1.1172)$ & $(0.0009)$ \\
\hline \multirow[t]{2}{*}{$H I G H S K I L L$} & -0.0165 & 0.0058 & $4.7758^{* * *}$ & 0.0009 \\
\hline & $(0.0176)$ & $(0.0115)$ & $(1.7802)$ & $(0.0013)$ \\
\hline Joint significance of $S K I L L$ & $3.45^{* *}$ & 1.52 & $3.60^{* *}$ & 0.22 \\
\hline Number of parameters & 223 & 223 & 223 & 223 \\
\hline Number of individuals & 14,028 & 14,028 & 14,028 & 14,028 \\
\hline Number of observations & 771,54 & 686,218 & 674,767 & 771,54 \\
\hline
\end{tabular}

Notes: The regression analyses include, besides the covariates, multiple three-way interaction terms. Three-way interaction terms are included among the variables DISPLACED, POST and LTV, among the variables DISPLACED, POST and S KILL and among the variables DISPLACED, POST and all other covariates. The reference category of $S K I L L$ consists of workers who attained lower education. See Table 2 for additional notes.

\section{Table B5}

The role of homeownership and continuous LTV in the effects of job displacement (Eq. (3)).

\begin{tabular}{|c|c|c|c|c|}
\hline & $\begin{array}{l}\text { Employment } \\
\qquad(=1)\end{array}$ & $\begin{array}{l}\text { Hourly wage } \\
\quad(\log )\end{array}$ & $\begin{array}{l}\text { Commuting distance } \\
(\mathrm{km})\end{array}$ & $\begin{array}{l}\text { Home change } \\
\qquad(=1)\end{array}$ \\
\hline & (1) & (2) & (3) & (4) \\
\hline \multicolumn{5}{|l|}{ DISPLACED $\times P O S T \times$} \\
\hline \multicolumn{5}{|l|}{ Housing state: } \\
\hline \multirow[t]{2}{*}{ HOMEOWNERS HIP } & $0.0193^{* *}$ & 0.0048 & -0.0153 & 0.0005 \\
\hline & $(0.0088)$ & $(0.0057)$ & $(0.7604)$ & $(0.0006)$ \\
\hline \multirow[t]{2}{*}{ CONTINUOUS LTV } & $0.0002^{* *}$ & $-0.0003^{* * *}$ & -0.0044 & 0 \\
\hline & $(0.0001)$ & $(0.0001)$ & $(0.0089)$ & $(0)$ \\
\hline Number of parameters & 208 & 208 & 208 & 208 \\
\hline Number of individuals & 54,229 & 54,229 & 54,229 & 54,229 \\
\hline Number of observations & $2,982,594$ & $2,719,569$ & $2,686,297$ & $2,982,594$ \\
\hline
\end{tabular}




\section{Appendix C Summary Statistics}

Table C.1 provides multiple statistics that improve our understanding of the within change in hourly wage and commuting distance for the displaced and non-displaced. The within change is calculated by taking the difference between the values of each variable eighteen months after job displacement and the month of potential or actual job displacement.

The displaced are characterised by a decrease in the hourly wage and the non-displaced by an increase in hourly wage. Half of all displaced workers experience no or a modest decline in commuting distance. For the displaced, the within hourly wage change follows a distribution with a long tail to the left. For the non-displaced, the within hourly wage change follows a distribution with a long tail to the right.

Half of all displaced workers experience a sharp increase in commuting distance after job displacement. The mean within change in the commuting distance for the non-displaced is close to zero. Only the bottom and top 5 per cent experience a relatively small decrease and increase, respectively. The within commuting change has a substantial skewness and follows an asymmetrical distribution with a long tail to the right, especially for the displaced.

Appendix D Robustness Checks for the Empirical Models on Margins of Adjustment 
Table C1

The within change in hourly wage and commuting distance for displaced and non-displaced workers.

\begin{tabular}{lccccc}
\hline & \multicolumn{2}{c}{$\begin{array}{c}\text { Hourly wage } \\
(\log )\end{array}$} & & \multicolumn{2}{c}{$\begin{array}{c}\text { Commuting distance } \\
(\mathrm{km})\end{array}$} \\
\cline { 2 - 3 } \cline { 5 - 6 } & Displaced & Non-displaced & & Displaced & Non-displaced \\
\hline Mean & -0.0245 & 0.0414 & & 3.6006 & 0.2691 \\
St. Dev. & 0.3116 & 0.1786 & & 32.3825 & 14.8189 \\
Variance & 0.0971 & 0.0319 & & $1,048.6236$ & 219.6010 \\
Skewness & -0.9973 & 1.1729 & & 1.1568 & 0.2277 \\
Kurtosis & 31.2475 & 55.6833 & & 14.4843 & 54.4108 \\
1th percentile & -0.9594 & -0.4967 & & -95.3368 & -49.6782 \\
5th percentile & -0.4577 & -0.1572 & & -38.1269 & -6.6214 \\
25th percentile & -0.1247 & -0.0010 & & -1.8662 & 0 \\
50th percentile & 0.0018 & 0.0338 & & 0 & 0 \\
75th percentile & 0.0979 & 0.0871 & & 8.9507 & 0 \\
95th percentile & 0.3351 & 0.2462 & & 51.5134 & 9.3275 \\
99th percentile & 0.7473 & 0.5854 & & 129.5867 & 54.6074 \\
\hline Number of observations & 15,196 & 32,693 & & 14,551 & 32,483 \\
\hline
\end{tabular}

Notes: The individual summary statistics are based on the within change, measured by the difference in the values of each variable between the eighteenth month after job displacement and the month of job displacement.

Table C2

Individual summary statistics using the non-matched sample.

\begin{tabular}{|c|c|c|c|c|c|}
\hline & \multicolumn{2}{|c|}{ Non-displaced } & \multicolumn{2}{|c|}{ Displaced } & \multirow[b]{2}{*}{$t$-statistic } \\
\hline & Mean & St. Dev. & Mean & St. Dev & \\
\hline Employment (=1) & 1 & 0 & 1 & 0 & \\
\hline Hourly wage (log) & 2.8579 & 0.3796 & 2.7951 & 0.4176 & $29.48^{* * *}$ \\
\hline Hourly wage $(€)$ & 18.8743 & 11.261 & 18.6003 & 41.4605 & $4.31^{* * *}$ \\
\hline Commuting distance $(\mathrm{km})$ & 14.8073 & 21.1692 & 17.5219 & 24.8161 & $-22.88^{* * *}$ \\
\hline Home change $(=1)$ & 0.004 & 0.0632 & 0.0044 & 0.0661 & -1.07 \\
\hline $\operatorname{LTV}(\%)$ & 59.5615 & 32.8507 & 60.6925 & 33.4721 & $-5.23^{* * *}$ \\
\hline LTI ratio & 2.9782 & 28.1622 & 2.8718 & 3.4081 & 0.67 \\
\hline Mortgage debt $(€)$ & 120,461 & 115,406 & 111,089 & 113,978 & $14.49^{* * *}$ \\
\hline Property value $(€)$ & 215,537 & 222,552 & 197,057 & 284,727 & $14.81^{* * *}$ \\
\hline Non-housing wealth $(€)$ & 66,307 & 277,218 & 55,221 & 219,700 & $7.14^{* * *}$ \\
\hline Annual household income (€) & 44,152 & 21,141 & 42,026 & 22,134 & $17.95^{* * *}$ \\
\hline Age (in years) & 43.8438 & 8.5612 & 43.0404 & 8.7444 & $16.74^{* * *}$ \\
\hline Female $(=1)$ & 0.4381 & 0.4962 & 0.2692 & 0.4435 & $60.77^{* * *}$ \\
\hline Dutch $(=1)$ & 0.9116 & 0.2839 & 0.9022 & 0.2971 & $5.90^{* * *}$ \\
\hline Partner $(=1)$ & 0.6223 & 0.4848 & 0.5971 & 0.4905 & $9.30^{* * *}$ \\
\hline No child $(=1)$ & 0.5192 & 0.4996 & 0.5316 & 0.499 & $-4.42^{* * *}$ \\
\hline Household members (\#) & 3.0033 & 1.3089 & 2.9828 & 1.3043 & $2.81^{* * *}$ \\
\hline Fixed contract $(=1)$ & 0.9539 & 0.2097 & 0.9166 & 0.2766 & $31.77^{* * *}$ \\
\hline Full-time job $(=1)$ & 0.6039 & 0.4891 & 0.7215 & 0.4483 & $-42.92^{* * *}$ \\
\hline Tenure in the job (in months) & 148.9688 & 94.051 & 132.5316 & 87.3091 & $31.19^{* * *}$ \\
\hline Manufacturing sector $(=1)$ & 0.2497 & 0.4328 & 0.4759 & 0.4994 & $-93.24^{* * *}$ \\
\hline $\begin{array}{l}\text { Duration of home occupancy } \\
\text { (in months) }\end{array}$ & 106.8996 & 58.4576 & 108.0195 & 59.7186 & $-3.42^{* * *}$ \\
\hline
\end{tabular}

Number of individuals (\#) 24,043,844 31,888
Notes: The individual summary statistics, provided for the month of actual or potential displacement, are based on the
sample prior to matching. The time period under observation is from July 2007 to December 2011. Sample means with
standard deviations are provided for the treatment group and control group. The $t$-statistic is provided to assess whether the
mean and standard deviation of each variable for the groups of displaced and non-displaced workers are statistically different
from each other. ${ }^{* * * * * *}, *$, correspond to the significance level of $1 \%, 5 \%, 10 \%$, respectively. By construction, all displaced
and non-displaced were employed in the month of actual or potential displacement.


Table C3

Individual summary statistics using the matched sample.

\begin{tabular}{|c|c|c|c|c|c|}
\hline & \multicolumn{2}{|c|}{ Non-displaced } & \multicolumn{2}{|c|}{ Displaced } & \multirow[b]{2}{*}{$t$-statistic } \\
\hline & Mean & St. Dev. & Mean & St. Dev & \\
\hline Employment (=1) & 1 & 0 & 1 & 0 & \\
\hline Hourly wage (log) & 2.8426 & 0.3686 & 2.8314 & 0.4101 & $3.30^{* * *}$ \\
\hline Hourly wage $(€)$ & 18.4981 & 8.8651 & 19.1812 & 38.6269 & $-3.13^{* * *}$ \\
\hline Commuting distance $(\mathrm{km})$ & 15.0456 & 21.5756 & 17.2607 & 24.4967 & $-10.98^{* * *}$ \\
\hline Home change $(=1)$ & 0.0043 & 0.0651 & 0.0036 & 0.0597 & 1.22 \\
\hline $\operatorname{LTV}(\%)$ & 59.4587 & 31.7348 & 59.7254 & 31.9765 & -0.81 \\
\hline LTI ratio & 2.8357 & 2.9655 & 2.8737 & 3.3361 & -1.38 \\
\hline Mortgage debt $(€)$ & 115,651 & 110,932 & 113,492 & 111,257 & $2.19^{* *}$ \\
\hline Property value $(€)$ & 208,041 & 201,155 & 205,066 & 334,756 & 1.29 \\
\hline Non-housing wealth $(€)$ & 59,137 & 197,274 & 53,153 & 181,760 & $3.51^{* * *}$ \\
\hline Annual household income $(€)$ & 43,279 & 20,449 & 42,812 & 22,963 & $2.45^{* *}$ \\
\hline Age (in years) & 43.4753 & 8.7785 & 43.537 & 8.7269 & -0.79 \\
\hline Female $(=1)$ & 0.2093 & 0.4069 & 0.2137 & 0.4099 & -1.19 \\
\hline Dutch $(=1)$ & 0.9525 & 0.2127 & 0.9457 & 0.2267 & $3.54^{* * *}$ \\
\hline Partner $(=1)$ & 0.6439 & 0.4789 & 0.6369 & 0.4809 & 1.63 \\
\hline No child $(=1)$ & 0.513 & 0.4998 & 0.5227 & 0.4995 & $-2.17^{* *}$ \\
\hline Household members (\#) & 3.0727 & 1.3076 & 3.0375 & 1.2991 & $3.03^{* * *}$ \\
\hline Fixed contract $(=1)$ & 0.979 & 0.1432 & 0.9719 & 0.1652 & $5.29^{* * *}$ \\
\hline Full-time job $(=1)$ & 0.7946 & 0.404 & 0.784 & 0.4115 & $2.93^{* * *}$ \\
\hline Tenure in the job (in months) & 143.0305 & 90.6646 & 142.8202 & 91.7574 & 0.26 \\
\hline Manufacturing sector $(=1)$ & 0.5266 & 0.4993 & 0.5209 & 0.4996 & 1.28 \\
\hline Duration of home occupancy (in months) & 110.0975 & 59.4983 & 111.1839 & 59.5814 & $-2.05^{* *}$ \\
\hline Number of individuals (\#) & \multicolumn{2}{|c|}{34,077} & \multicolumn{2}{|c|}{20,152} & \\
\hline
\end{tabular}

Notes: The individual summary statistics, provided for the month of actual or potential displacement, are based on the sample after matching. The time period under observation is from July 2007 to December 2011. Sample means with standard deviations are provided for the treatment group and control group. The $t$-statistic is provided to assess whether the mean and standard deviation of each variable for the groups of displaced and non-displaced workers are statistically different from each other. ${ }^{* * *},{ }^{* *},{ }^{*}$, correspond to the significance level of $1 \%$, $5 \%, 10 \%$, respectively. By construction, all displaced and non-displaced were employed in the month of actual or potential displacement.

Table C4

Number of matched individuals.

\begin{tabular}{|c|c|c|c|}
\hline & \multicolumn{3}{|c|}{ Number of individuals } \\
\hline & Displaced & Non-displaced & All \\
\hline & (1) & (2) & (3) \\
\hline \multicolumn{4}{|l|}{ Housing state: } \\
\hline Tenant & 5,256 & 8,804 & 14,060 \\
\hline$L T V=0 \%$ & 537 & 812 & 1,349 \\
\hline $0<L T V \leq 33 \%$ & 2,959 & 5,124 & 8,083 \\
\hline $33<L T V \leq 66 \%$ & 4,843 & 8,347 & 13,190 \\
\hline $66<L T V \leq 100 \%$ & 4,796 & 8,193 & 12,989 \\
\hline $100<L T V \leq 133 \%$ & 1,761 & 2,797 & 4,558 \\
\hline Total & 20,152 & 34,077 & 54,229 \\
\hline
\end{tabular}

Notes: The number of matched individuals is provided for each housing state and treatment group. 
Table C5

Firm summary statistics in the month of job displacement.

\begin{tabular}{|c|c|c|c|c|}
\hline & \multicolumn{4}{|c|}{ Firms } \\
\hline & \multicolumn{2}{|c|}{ Bankrupt firms } & \multicolumn{2}{|c|}{ Non-bankrupt firms } \\
\hline & Mean & St. Dev. & Mean & St. Dev. \\
\hline \multicolumn{5}{|l|}{ Firm size: } \\
\hline 1-9 employees $(=1)$ & 0 & 0 & 0 & 0 \\
\hline 10-49 employees $(=1)$ & 0.7247 & 0.4467 & 0.6258 & 0.4839 \\
\hline $50-99$ employees $(=1)$ & 0.1114 & 0.3147 & 0.1400 & 0.3470 \\
\hline 100-499 employees $(=1)$ & 0.1025 & 0.3033 & 0.1702 & 0.3758 \\
\hline 500 or more employees $(=1)$ & 0.0614 & 0.2401 & 0.0640 & 0.2447 \\
\hline \multicolumn{5}{|l|}{ Firm sector: } \\
\hline Agriculture, forestry and fishing $(=1)$ & 0.0099 & 0.0991 & 0.0042 & 0.0644 \\
\hline Mining and quarrying $(=1)$ & 0 & 0 & 0 & 0 \\
\hline Manufacturing $(=1)$ & 0.2415 & 0.4280 & 0.3474 & 0.4762 \\
\hline Electricity, gas, steam and air conditioning supply $(=1)$ & 0 & 0 & 0 & 0 \\
\hline Water supply; sewerage, waste management and remediation $(=1)$ & 0.0010 & 0.0311 & 0.0002 & 0.0136 \\
\hline Construction $(=1)$ & 0.1951 & 0.3963 & 0.2010 & 0.4008 \\
\hline Wholesale and retail trade; repair of motor vehicles and cycles $(=1)$ & 0.1999 & 0.4000 & 0.2207 & 0.4147 \\
\hline Transportation and storage $(=1)$ & 0.0691 & 0.2537 & 0.0515 & 0.2209 \\
\hline Accommodation and food service activities $(=1)$ & 0.0121 & 0.1093 & 0.0041 & 0.0636 \\
\hline Information and communication $(=1)$ & 0.0372 & 0.1893 & 0.0163 & 0.1268 \\
\hline Financial and insurance activities $(=1)$ & 0.0321 & 0.1764 & 0.0274 & 0.1634 \\
\hline Real estate activities $(=1)$ & 0.0041 & 0.0640 & 0.0012 & 0.0343 \\
\hline Professional, scientific and technical activities $(=1)$ & 0.0851 & 0.2790 & 0.0542 & 0.2265 \\
\hline Administrative and support service activities $(=1)$ & 0.0645 & 0.2457 & 0.0315 & 0.1746 \\
\hline Public administration and defence; compulsory social security $(=1)$ & 0 & 0 & 0 & 0 \\
\hline Education $(=1)$ & 0.0065 & 0.0805 & 0.0052 & 0.0717 \\
\hline Human health and social work activities $(=1)$ & 0.0317 & 0.1751 & 0.0314 & 0.1743 \\
\hline Arts, entertainment and recreation $(=1)$ & 0.0034 & 0.0581 & 0.0011 & 0.0338 \\
\hline Other service activities $(=1)$ & 0.0068 & 0.0820 & 0.0027 & 0.0518 \\
\hline Activities of households as employers and for own use $(=1)$ & 0 & 0 & 0 & 0 \\
\hline Activities of extraterritorial organisations and bodies $(=1)$ & 0 & 0 & 0 & 0 \\
\hline Number of firms (\#) & \multicolumn{2}{|c|}{4,137} & \multicolumn{2}{|c|}{27,109} \\
\hline
\end{tabular}

Notes: Means and standard deviations are provided at the firm level. The time period under observation is from July 2007 to December 2011. Bankrupts firms consist of all distinct firms of which an entity is declared bankrupt and a worker is displaced in the month of actual displacement. Non-bankrupt firms consist of all distinct firms where matched non-displaced workers work in the month of potential displacement. 
Table C6

Individual summary statistics for each housing state using the matched sample.

\begin{tabular}{|c|c|c|c|c|c|c|}
\hline & \multicolumn{6}{|c|}{ Housing state } \\
\hline & \multirow[b]{2}{*}{ Tenant } & \multicolumn{5}{|c|}{ LTV } \\
\hline & & $0 \%$ & $0-33 \%$ & $33-66 \%$ & $66-100 \%$ & $100-133 \%$ \\
\hline Employment (=1) & 1 & 1 & 1 & 1 & 1 & 1 \\
\hline Hourly wage (log) & 2.6505 & 2.8474 & 2.8877 & 2.9223 & 2.9296 & 2.8711 \\
\hline Hourly wage $(€)$ & 14.8504 & 18.4154 & 19.1421 & 20.0920 & 20.2513 & 18.9327 \\
\hline Commuting distance $(\mathrm{km})$ & 12.2651 & 13.3215 & 13.9457 & 16.0412 & 17.1179 & 17.2717 \\
\hline Home change $(=1)$ & 0.0081 & 0.0049 & 0.0023 & 0.0016 & 0.0032 & 0.0068 \\
\hline $\operatorname{LTV}(\%)$ & I & 0 & 19.8261 & 49.5076 & 83.0918 & 109.7967 \\
\hline LTI ratio & 0.0399 & 0 & 1.4240 & 3.3449 & 5.3308 & 6.2244 \\
\hline Mortgage debt $(€)$ & 1,467 & 0 & 62,635 & 140,532 & 215,205 & 239,894 \\
\hline Property value (€) & / & 328,333 & 330,791 & 285,318 & 260,397 & 219,108 \\
\hline Non-Housing Wealth $(€)$ & 23,576 & 219,632 & 94,881 & 66,394 & 56,354 & 45,496 \\
\hline Annual household income $(€)$ & 34,575 & 52,589 & 48,824 & 46,945 & 44,78 & 42,478 \\
\hline Age (in years) & 42.3176 & 46.4894 & 48.4207 & 46.1283 & 41.1604 & 36.0476 \\
\hline Female $(=1)$ & 0.2299 & 0.1268 & 0.1501 & 0.2155 & 0.2212 & 0.2242 \\
\hline $\operatorname{Dutch}(=1)$ & 0.8772 & 0.9938 & 0.9971 & 0.9835 & 0.9663 & 0.9632 \\
\hline Partner $(=1)$ & 0.4048 & 0.6170 & 0.8300 & 0.7944 & 0.6687 & 0.5409 \\
\hline No child (=1) & 0.6984 & 0.6995 & 0.5246 & 0.4222 & 0.3969 & 0.4655 \\
\hline Household members (\#) & 2.5125 & 3.1293 & 3.4461 & 3.3830 & 3.1767 & 2.9042 \\
\hline Fixed contract $(=1)$ & 0.9626 & 0.9840 & 0.9865 & 0.9865 & 0.9856 & 0.9743 \\
\hline Full-time job $(=1)$ & 0.8128 & 0.8399 & 0.7982 & 0.7657 & 0.7873 & 0.8259 \\
\hline Tenure in the job (in months) & 126.0956 & 175.5739 & 174.0796 & 162.0679 & 132.7751 & 103.2345 \\
\hline Manufacturing sector $(=1)$ & 0.5034 & 0.7020 & 0.6472 & 0.5401 & 0.4748 & 0.4394 \\
\hline $\begin{array}{l}\text { Duration of home occupancy } \\
\text { (in months) }\end{array}$ & 101.7157 & 144.5369 & 149.8603 & 127.7999 & 89.5446 & 61.0132 \\
\hline Number of observations (\#) & 5,256 & 537 & 2,959 & 4,843 & 4,796 & 1,761 \\
\hline
\end{tabular}

Notes: Sample means, based on the sample after matching, are provided for each housing state of the treatment group in the month of actual displacement. The time period under observation is from July 2007 to December 2011. By construction, all displaced and non-displaced are employed in the month of actual or potential displacement. The LTV and property value is observed if the worker is homeowner and not if the worker is tenant. Tenants can have a mortgage debt if they owned a home prior to their current rental home. 


\section{Table D1}

Two-way interaction model for sample of workers with full information on the firm location (Eq. (1)).

\begin{tabular}{|c|c|c|c|c|}
\hline & $\begin{array}{c}\text { Employment } \\
(=1)\end{array}$ & $\begin{array}{l}\text { Hourly wage } \\
\quad(\log )\end{array}$ & $\begin{array}{c}\text { Commuting distance } \\
(\mathrm{km})\end{array}$ & $\begin{array}{c}\text { Home change } \\
(=1)\end{array}$ \\
\hline & (1) & $(2)$ & (3) & (4) \\
\hline DISPLACED $\times$ POST & $\begin{array}{c}-0.2577^{* * *} \\
(0.0033)\end{array}$ & $\begin{array}{c}-0.0512^{* * *} \\
(0.0020)\end{array}$ & $\begin{array}{l}3.0087^{* * *} \\
(0.2824)\end{array}$ & $\begin{array}{c}-0.0006^{* * *} \\
(0.0002)\end{array}$ \\
\hline Number of parameters & 161 & 161 & 161 & 161 \\
\hline Number of individuals & 36,530 & 36,530 & 36,530 & 36,530 \\
\hline Number of observations & $2,009,150$ & $1,839,235$ & $1,839,235$ & $2,009,150$ \\
\hline
\end{tabular}

Notes: Each column gives the dependent variable. Clustered (by individual) standard errors are in parentheses. ${ }^{* * *},{ }^{* *},{ }^{*}$, correspond to the significance level of $1 \%$, $5 \%, 10 \%$, respectively. The reference category of DISPLACED and POST, consists of the non-displaced workers and pre-displacement period, respectively. The regression analyses include individual-specific fixed effects and indicator variables for housing state (5), age (3), children aged 18 or lower, partner, the number of household members (3), the NUTS 3 location of the household (39) and calendar month (107). The period under observation is from January 2006 to December 2014 The parameter estimates of the covariates and the main effect of POST are not reported.

Table D2

Two-way interaction model for sample with firms that have 49 employees at maximum (Eq. (1)).

\begin{tabular}{|c|c|c|c|c|}
\hline & $\begin{array}{c}\text { Employment } \\
(=1)\end{array}$ & $\begin{array}{l}\text { Hourly wage } \\
\quad(\log )\end{array}$ & $\begin{array}{l}\text { Commuting distance } \\
(\mathrm{km})\end{array}$ & $\begin{array}{l}\text { Home change } \\
(=1)\end{array}$ \\
\hline & $(1)$ & $(2)$ & (3) & $(4)$ \\
\hline DISPLACED $\times$ POST & $\begin{array}{c}-0.2338^{* * *} \\
(0.0035)\end{array}$ & $\begin{array}{c}-0.0515^{* * *} \\
(0.0023)\end{array}$ & $\begin{array}{l}3.9953^{* * *} \\
(0.2860)\end{array}$ & $\begin{array}{c}-0.0007^{* * *} \\
(0.0002)\end{array}$ \\
\hline Number of parameters & 161 & 161 & 161 & 161 \\
\hline Number of individuals & 27,375 & 27,375 & 27,375 & 27,375 \\
\hline Number of observations & $1,505,625$ & $1,375,974$ & $1,358,117$ & $1,505,625$ \\
\hline
\end{tabular}

Notes: Each column gives the dependent variable. Clustered (by individual) standard errors are in parentheses. ${ }^{* * *},{ }^{* *},{ }^{*}$, correspond to the significance level of $1 \%$, $5 \%, 10 \%$, respectively. The reference category of DISPLACED and POST, consists of the non-displaced workers and pre-displacement period, respectively. The regression analyses include individual-specific fixed effects and indicator variables for housing state (5), age (3), children aged 18 or lower, partner, the number of household members (3), the NUTS 3 location of the household (39) and calendar month (107). The period under observation is from January 2006 to December 2014. The parameter estimates of the covariates and the main effect of POST are not reported.

Table D3

Two-way interaction model for sample of workers who are matched on forty NUTS 3 areas (Eq. (1)).

\begin{tabular}{|c|c|c|c|c|}
\hline & $\begin{array}{c}\text { Employment } \\
(=1)\end{array}$ & $\begin{array}{l}\text { Hourly wage } \\
(\log )\end{array}$ & $\begin{array}{l}\text { Commuting distance } \\
(\mathrm{km})\end{array}$ & $\begin{array}{c}\text { Home change } \\
(=1)\end{array}$ \\
\hline & $(1)$ & $(2)$ & (3) & $(4)$ \\
\hline DISPLACED $\times$ POST & $\begin{array}{c}-0.2526^{* * *} \\
(0.0031)\end{array}$ & $\begin{array}{c}-0.0649^{* * *} \\
(0.0020)\end{array}$ & $\begin{array}{l}3.0940^{* * *} \\
(0.2790)\end{array}$ & $\begin{array}{l}-0.0003 \\
(0.0002)\end{array}$ \\
\hline Number of parameters & 161 & 161 & 161 & 161 \\
\hline Number of individuals & 35,756 & 35,756 & 35,756 & 35,756 \\
\hline Number of observations & $1,966,580$ & $1,782,424$ & $1,760,123$ & $1,966,580$ \\
\hline
\end{tabular}

Notes: Each column gives the dependent variable. Clustered (by individual) standard errors are in parentheses. ${ }^{* * *},{ }^{* *},{ }^{*}$, correspond to the significance level of $1 \%$, $5 \%, 10 \%$, respectively. The reference category of DISPLACED and POST, consists of the non-displaced workers and pre-displacement period, respectively. The regression analyses include individual-specific fixed effects and indicator variables for housing state (5), age (3), children aged 18 or lower, partner, the number of household members (3), the NUTS 3 location of the household (39) and calendar month (107). The period under observation is from January 2006 to December 2014. The parameter estimates of the covariates and the main effect of POST are not reported. 

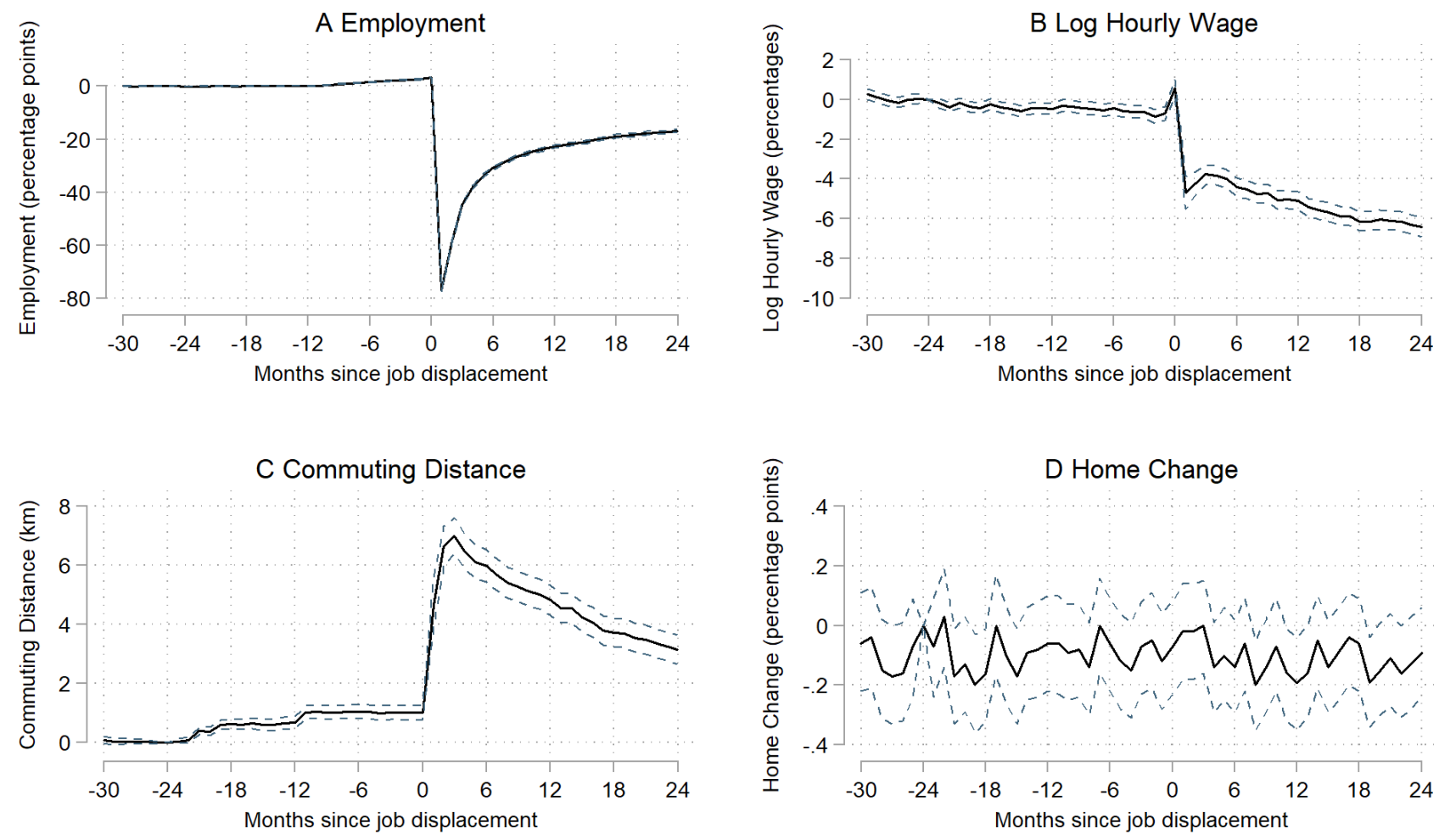

FE Coef.

95\% Conf. Int.

Fig. D1. Placebo treatment on employment (A), log hourly wage (B), commuting distance (C) and changing home (D) (Eq. (2)). Notes: Displaced workers are matched to non-displaced workers in the month of placebo treatment, i.e. the twelfth month prior to actual displacement. Reference group is the group of non-displaced workers. Reference month is the twenty-fourth month prior to job displacement. The 95\% confidence intervals are computed using standard errors clustered by individual. All four fixed effects regression models include 266 parameters of which there are 54 two-way interaction terms. See Table 1 for additional notes and statistics. 


\section{Appendix E Time-Dependent Differences in the Impor- tance of Demographic and Job Characteris- tics for the Displacement Effects}

Figures E.1-E.6 show the importance of demographic characteristics for the displacement effects. Figure E.1 highlights the gender differential in displacement effects. On the one hand, women experience a higher loss in employment than men. Importantly, the difference in the loss in employment diminishes over time since job displacement. On the other, women experience a smaller increase in the commuting distance than men. Figure E.2A and Figure E.2B show that age directly increases the loss in employment and hourly wage. The age differentials in the displacement effect on employment and hourly wage are relatively persistent over the post-displacement period. Figure E. 3 shows that the nationality differential in displacement effects varies across time since job displacement. The estimates show that displaced workers who have Dutch nationality experience relatively modest losses in employment.

Figures E.4-E.6 highlight the role of job characteristics in the displacement effects. Figure E.4A and Figure E.4B show that the worker's length of tenure in the displaced job, especially in the case of a job tenure higher than 18 years, increases the loss in employment and hourly wage, respectively. Figure E.4C shows that workers who had a relatively short job tenure experience the smallest increase in the commuting distance. Figure E.5 shows that displaced workers who were active in the manufacturing sector, as compared with the service sector, experience a substantial and persistent higher loss in the hourly wage of about 2-3 percentage points and a higher increase in the commuting distance of about 2 kilometres. The estimates shown in Figure E.6A indicate that workers who are displaced later in time experience a higher loss in employment and hourly wage. Figure E.6C shows that workers who were displaced in 2007 experience a relatively large increase in the commuting distance. This finding can be explained by a potential seasonality effect, as the workers who were displaced in 2007 were displaced between July to December. The other displacement cohorts consist of workers who were displaced in any month of the calendar year. 

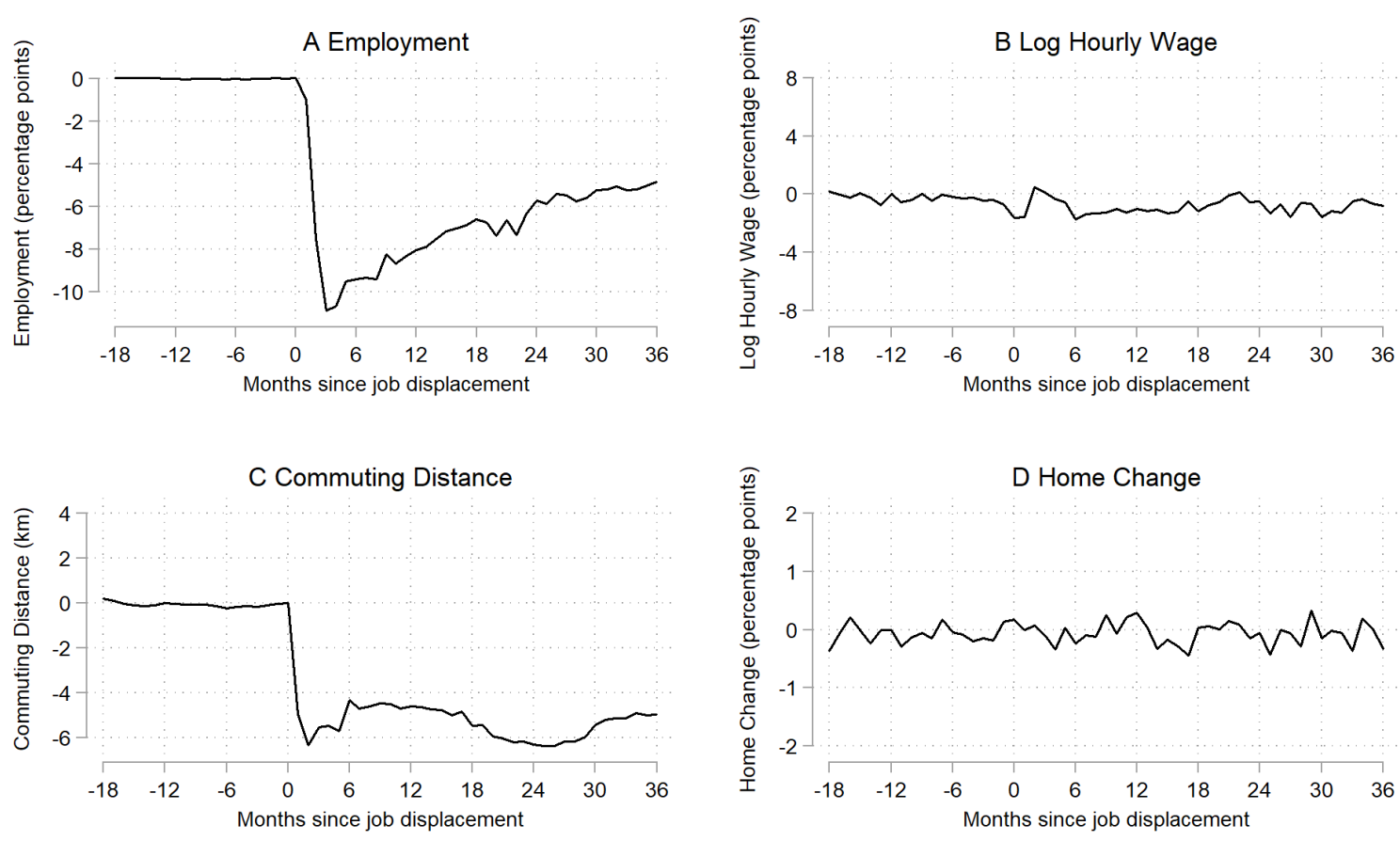

Women Base category: Men

Fig. E1. Gender differential in displacement effects (Eq. (4)). Notes: See Figure 1 and Table 2 for additional notes.
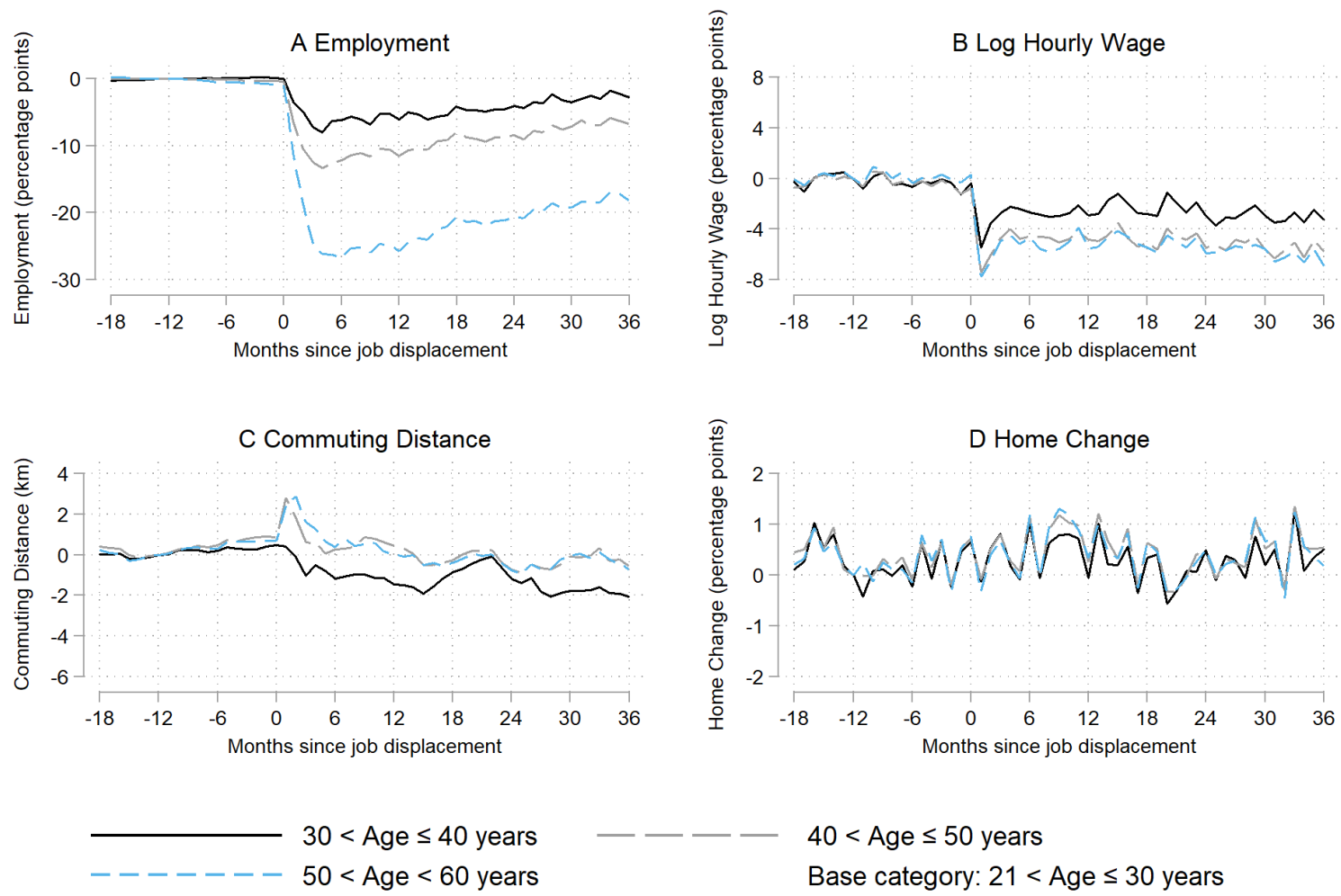

$40<$ Age $\leq 50$ years

Base category: $21<$ Age $\leq 30$ years

Fig. E2. Age differential in displacement effects (Eq. (4)). Notes: See Figure 1 and Table 2 for additional notes. 

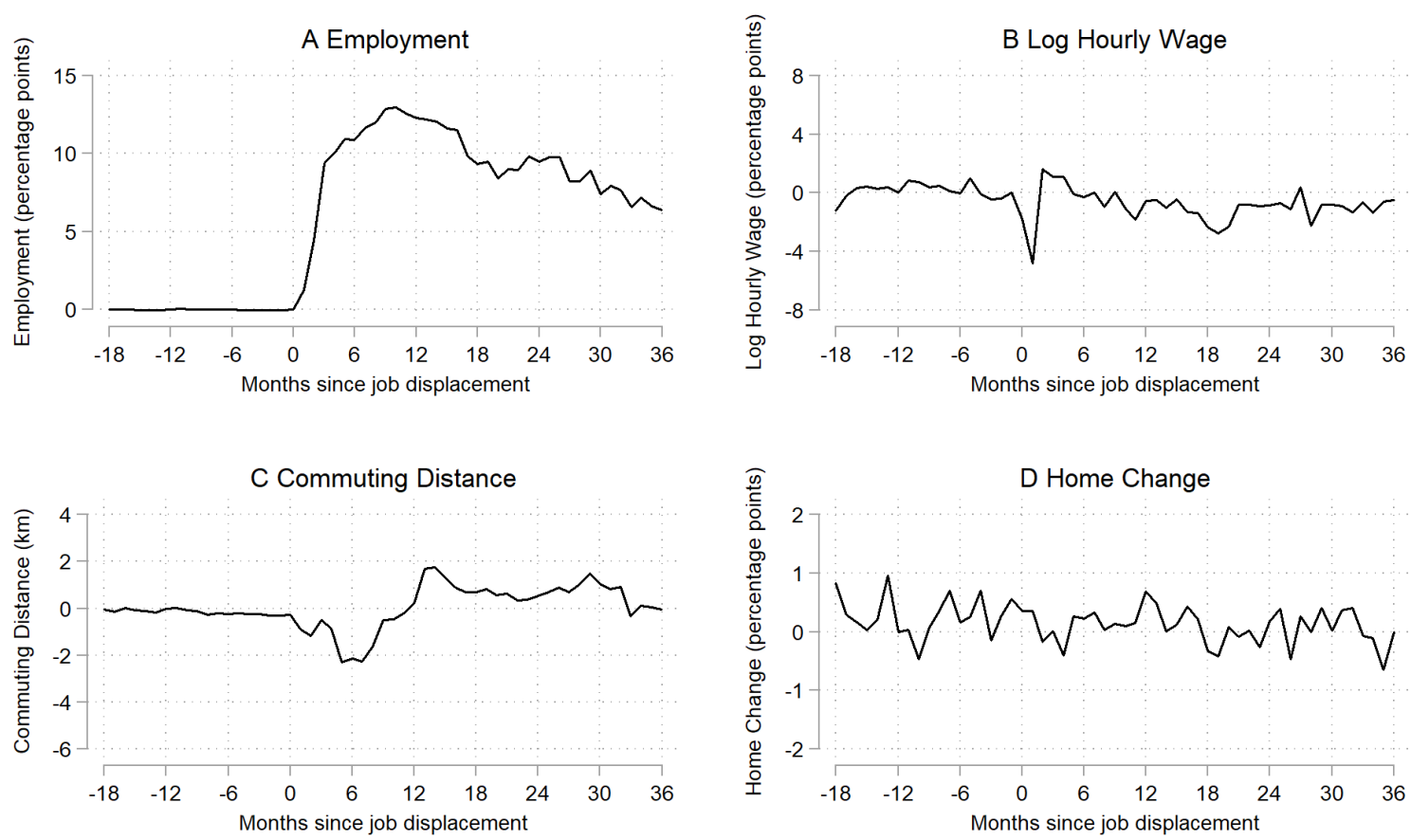

Dutch nationality

Base category: Non-Dutch nationality

Fig. E3. Nationality differential in displacement effects (Eq. (4)). Notes: See Figure 1 and Table 2 for additional notes.
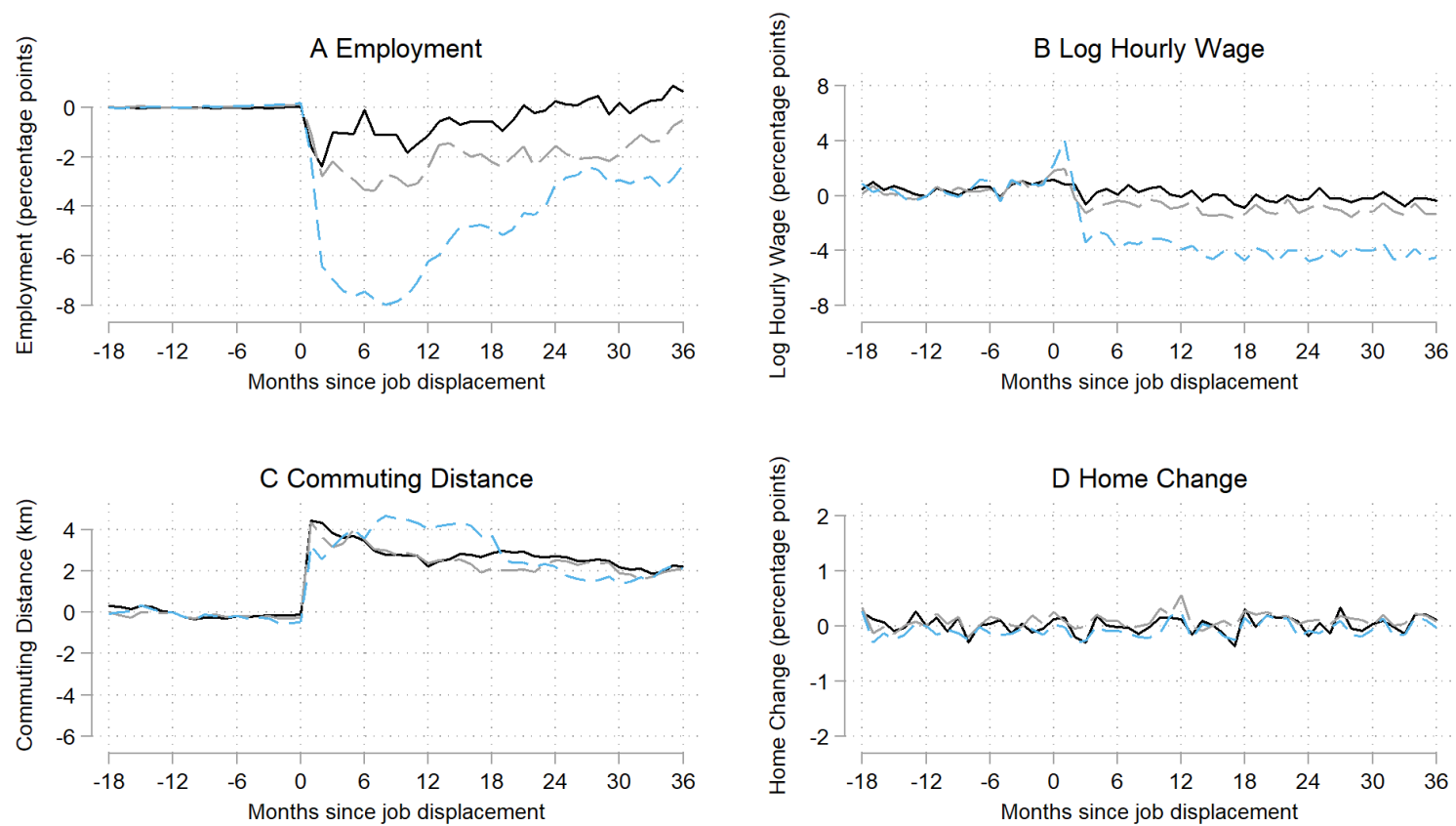

$6<$ Tenure $\leq 12$ years

Tenure $>18$ years

$12<$ Tenure $\leq 18$ years

Base category: $3<$ Tenure $\leq 6$ years

Fig. E4. Job tenure differential in displacement effects (Eq. (4)). Notes: See Figure 1 and Table 2 for additional notes. 

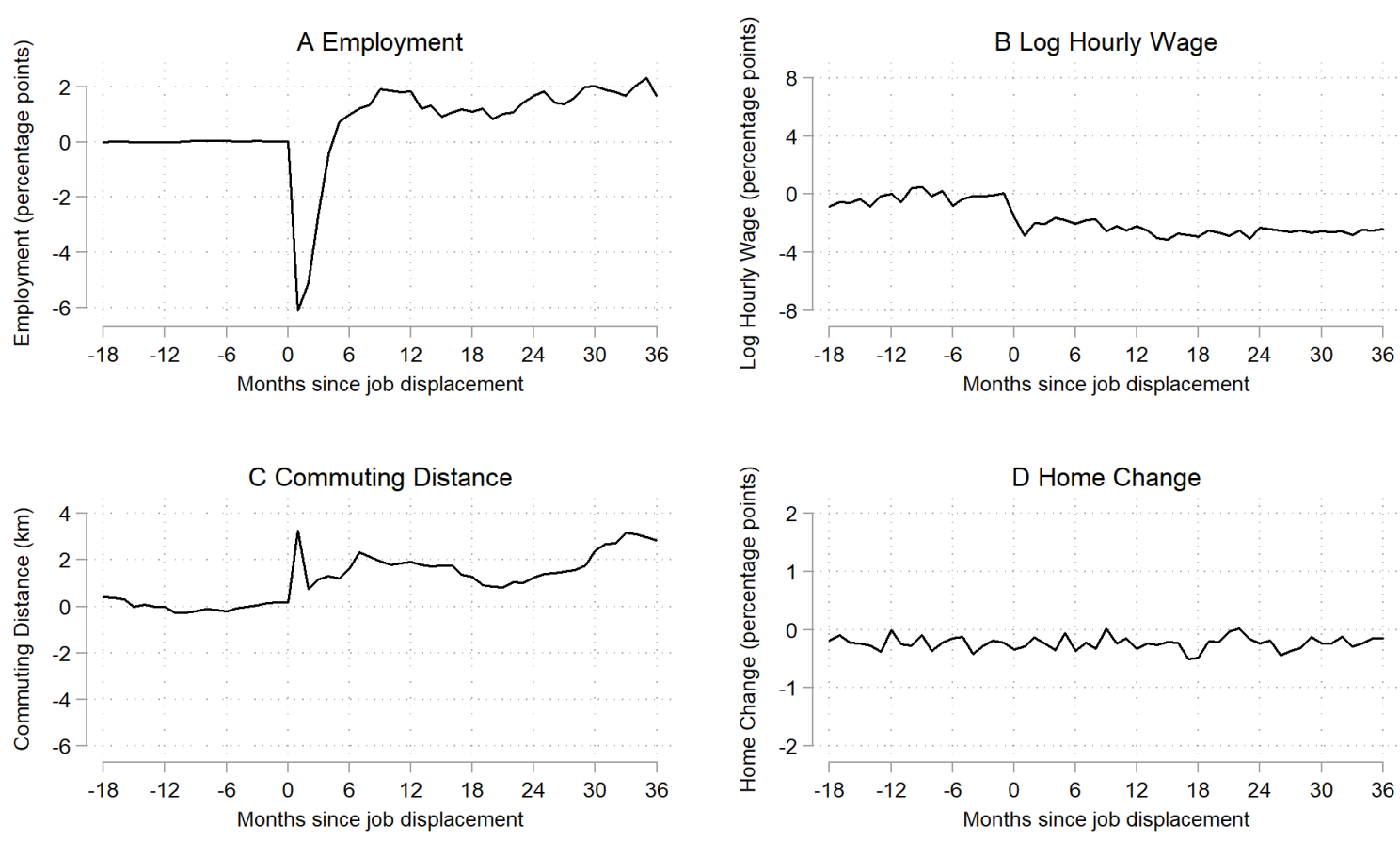

Manufacturing sector

Base category: Service sector

Fig. E5. Industry differential in displacement effects (Eq. (4)). Notes: See Figure 1 and Table 2 for additional notes.
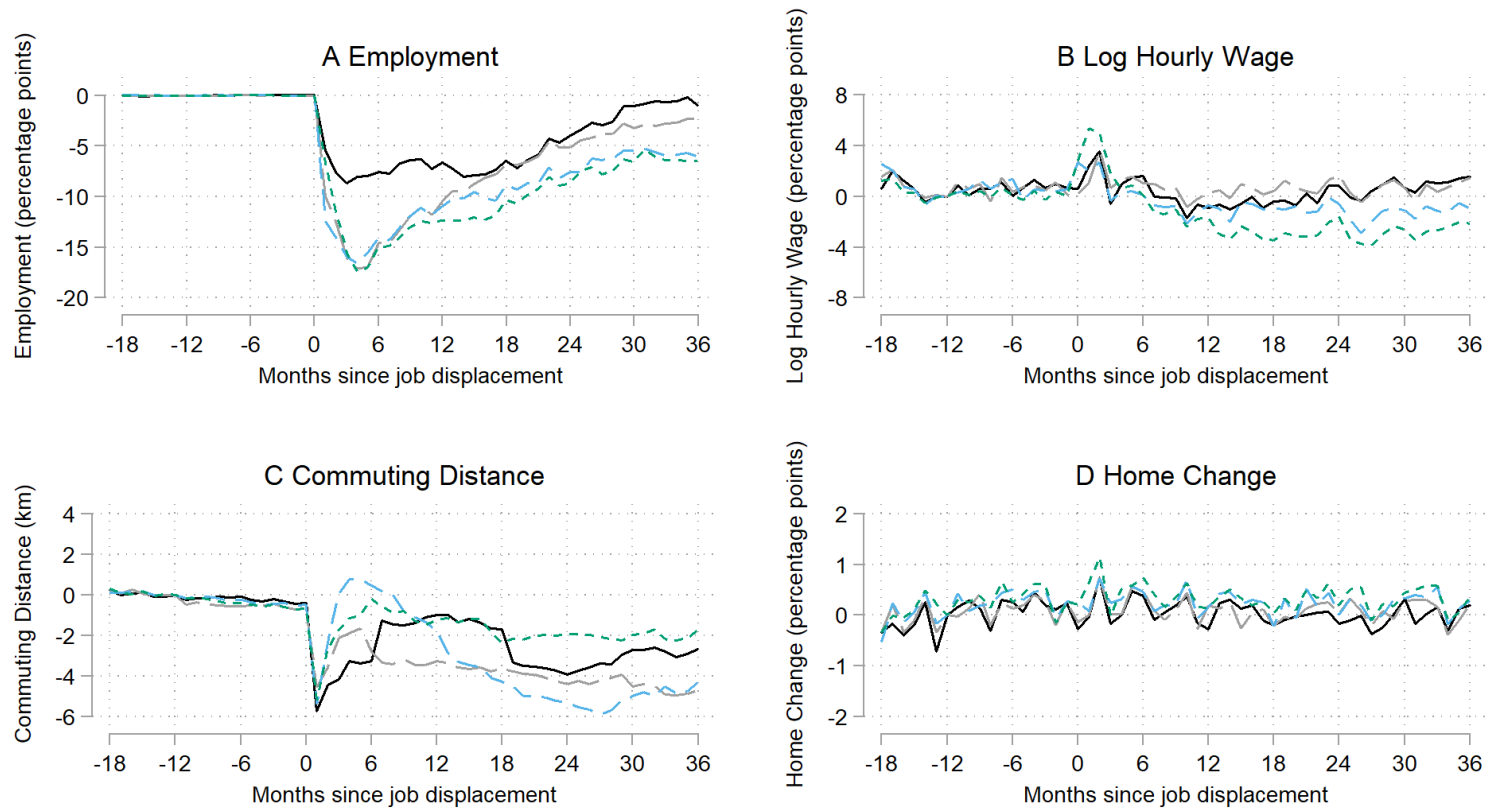

Displacement year 2008

Displacement year 2009

Displacement year 2010

Displacement year 2011

Base category: Displacement year 2007

Fig. E6. Displacement year differential in displacement effects (Eq. (4)). Notes: See Figure 1 and Table 2 for additional notes. 


\section{Appendix F Coarsened Exact Matching Procedure}

In a matching algorithm there is the trade-off between efficiency and lower bias, i.e. the choice between complete matching and exact matching (Rubin, 2006, Caliendo and Kopeinig 2008). Exact matching ensures a high quality of matching as the amount of imbalance between matched treated and controls is controlled and limited. However, CEM does not lead to complete matching. Complete matching is achieved if all treated are matched with at least one control. We performed CEM of treated to controls as we prefer a lower bias to efficiency gains. Moreover, we had the opportunity to exploit rich administrative data with a high number of potential controls. Exact matching on coarsened observables ensured that the treated and controls were observably equivalent.

Workers who were displaced due to firm bankruptcy are referred to as treated. The non-displaced are referred to as controls. In the month of job displacement, the treated were matched with a potential match of the group of controls. The controls were required to stay employed in the month of separation of the treated. Each treated was matched with a maximum of two controls. Note that the potential month of displacement of the matched control is equivalent to the actual month of job displacement of the matched treated. Except for job displacement due to firm bankruptcy, the controls were exposed to similar risks of labour turnover as the treated. Exposure of controls to other reasons for job loss is important to avoid overestimates of the displacement effects (Krolikowski, 2017). These risks represent voluntary labour turnover and involuntary labour turnover. The treated or the matched controls were not allowed to be the counterfactual of another treated worker in the other months under observation. For this reason, the order of months in the period July 2007 to December 2011, in which we separately match treated workers with control workers, was taken randomly.

Before we applied CEM, the non-matched sample consisted of 31,888 treated workers. See Table C.2 in Appendix C for individual summary statistics for the treated and controls based on the non-matched sample. The default set of matching variables we incorporated in the matching process consists of indicator variables for gender, age (21-30; 30-35; 35-40; 40-45; 45-50 and 50-60 years), children aged 18 or lower, partner, Dutch nationality, tenancy, LTV (0; 0-33; 33-66; 66-100 and 100-133 per cent), type of job (full-time or part-time), type of contract (fixed or temporary), job tenure (3-6; 6-12; 12-18 and over 18 years), work location (twelve provinces), firm size (10-49; 50-99; 100-499 and 500 or more employed workers), firm industry (twenty-one ISIC sectors), calendar month and calendar year. The matched sample consisted of 20,152 treated workers, which implies a matching rate of 63 per cent. See Table C.3 in Appendix Cfor individual summary statistics of the treated and controls based on the matched sample.

The matching procedure we applied to balance treated and controls in covariates was successful. Based on the comparison of Table C. 3 to Table C. 2 in Appendix C, we observe that the difference in sample means between the treated and controls was smaller after matching and many became economically insignificant. See Table C. 4 for an overview of the number of matched individuals by housing state and treatment group. See Table C.5 for firm size and firm sector summary statistics in the month of job actual displacement. See Table C.6 for individual summary statistics distinguished by workers' housing state.

To assess the implications of incomplete matching, we matched on the work location at the NUTS 3 level (forty areas) instead of at the provincial level (twelve areas). The matched sample consisted of 14,284 matched treated workers. The matching rate decreased from 68 per cent to 45 per cent. Table D. 3 shows that the results are robust to a difference in the matching rate and matching on the NUTS 3 area.

As a robustness check, we matched not only on the default set of matching variables, but also on the worker's categories of the non-housing wealth position (below $0 ; 0-5,000 ; 5,000$ 25,$000 ; 25,000-75,000$ and over 75,000 euro) and duration of home occupancy (0-60; 60-180 and over 180 months). In this case, the number of matched treated was 10,128 . In a separate robustness check, we used both the loan-to-income (LTI) ratio and LTV as approximations of household leverage. Note that we prefer the LTV to the LTI ratio as our main approximation of household leverage, because the LTV allows for within variation caused by changes in the property value and the mortgage debt. The LTI ratio does not allow for within variation caused by changes in income, as job displacement generates an artificial loss in income. For this robustness check, we matched not only on the default set of matching variables, but also on the LTI ratio categories $(0-1.5 ; 1.5-3.0,3.0-4.5 ; 4.5-6.0$ and over 6.0$)$. This approach resulted in 16,222 matched treated workers. As a final robustness check, we matched not only on the default set of matching variables, but also on the skill level (i.e. low, medium and high education). Matching on the skill level resulted in a relatively low number of 5,841 matched treated workers. The low number of matched treated individuals was caused by the selectivity of education data, as the education data were only available for individuals if they received their diploma after 1995. The three robustness checks are discussed in Appendix B 